\title{
Intellectual Functioning in Old and Very Old Age: Cross-Sectional Results From the Berlin Aging Study
}

\author{
Ulman Lindenberger and Paul B. Baltes \\ Max Planck Institute for Human Development and Education
}

\begin{abstract}
This study documents age trends, interrelations, and correlates of intellectual abilities in old and very old age (70-103 years) from the Berlin Aging Study $(N=516)$. Fourteen tests were used to assess 5 abilities: reasoning, memory, and perceptual speed from the mechanic (broad fluid) domain and knowledge and fluency from the pragmatic (broad crystallized) domain. Intellectual abilities had negative linear age relations, with more pronounced age reductions in mechanic than in pragmatic abilities. Interrelations among intellectual abilities were highly positive and did not follow the mechanic-pragmatic distinction. Sociobiographical indicators were less closely linked to intellectual functioning than sensory-sensorimotor variables, which predicted $59 \%$ of the total reliable variance in general intelligence. Results suggest that aging-induced biological factors are a prominent source of individual differences in intelligence in old and very old age.
\end{abstract}

This article provides the first comprehensive overview summary regarding the structure and correlates of intellectual functioning as they were observed in the full sample of the intensive data protocol of the Berlin Aging Study (BASE; $N=516$, mean age $=85$ years, and age range $=70-103$ years , an ongoing multidisciplinary and longitudinal study of old age and aging. To some degree, the present analysis replicates and extends two earlier articles that were based on an initial subset of BASE research participants $(N=156$; Lindenberger \& Baltes, 1994b; Lindenberger, Mayr, \& Kliegl, 1993). Moreover, some of the findings reported in this article have been published before in German-language publications (Lindenberger \& Baltes, 1995; Reischies \& Lindenberger, 1996). Given the scarcity of comparable data for this segment of the life span, our primary goal in this contribution was to document and describe intellectual abilities in old and very old age - their age gradients and intercorrelations, their age-based differences in various aspects of variability, and their "embeddedness" in sociobiographical as well as aging-related biological systems of influence.

In addition, a related but secondary goal of the present study was to link the major findings emanating from this descriptive

The present research was conducted in the context of the Berlin Aging Study (BASE), which is co-chaired by Paul B. Baltes and Karl Ulrich Mayer (for more information, see the author note in Paul B. Baltes and Jacqui Smith, this issue, p. 395).

We thank our present and past colleagues within BASE for their cooperation, especially Markus Borchelt, Reiner Gilberg, Reinhold Kliegl, Michael Marsiske, Ulrich Mayr, Ulrich Pötter, Friedel Reischies, Hans Scherer, Jacqui Smith, Ursula Staudinger, and Michael Wagner. In addition, we thank Peter Frensch, Chris Hertzog, Shu-Chen Li, Todd Little, Elizabeth Maylor, and Paul Verhaeghen for helpful discussions regarding various issues covered in this article.

Correspondence concerning this article should be addressed to either Ulman Lindenberger or Paul B. Baltes, Center for Psychology and Human Development, Max Planck Institute for Human Development and Education, Lentzeallee 94, 14195 Berlin, Germany. Electronic mail may be sent to lindenberger@mpib-berlin.mpg.de. enterprise to central themes and concepts of life span theory ( $\mathrm{P}$. B. Baltes, Lindenberger, \& Staudinger, in press) and cognitive aging research (Craik \& Salthouse, 1992; Lindenberger \& Baltes, 1994a). Typical examples of such themes and concepts include the two-component model of life span cognition (P. B. Baltes, 1987, 1993; cf. Cattell, 1971, Horn, 1982), the dedifferentiation hypothesis of intellectual aging (P. B. Baltes, Cornelius, Spiro, Nesselroade, \& Willis, 1980; Reinert, 1970; Schaie, Willis, Jay, \& Chipuer, 1989; cf. Deary \& Pagliari, 1991; Garrett, 1946; Lienert \& Crott, 1964; Spearman, 1927), and the dimensionality of negative age differences in late-life intellectual functioning (Perfect, 1994; Salthouse, 1996). Finally, given the cross-sectional character of our observations and the high mean age of the present sample, we occasionally comment on the complex relations between interindividual age differences, intraindividual age changes, and selective mortality.

\section{General Features of the Berlin Aging Study (BASE)}

As described in more detail elsewhere (P. B. Baltes, Mayer, Helmchen, \& Steinhagen-Thiessen, 1993, 1996; P. B. Baltes \& Smith, 1997; Lindenberger, Gilberg, Little, Nuthmann, Pötter, \& Baltes, in press; Lindenberger, Gilberg, Pötter, Little, \& Baltes, 1996), the design of BASE has three central features. First, all BASE samples derive from random draws of addresses from obligatory state registry records, which presumably results in data with a relatively high degree of generalizability and heterogeneity compared with data obtained through other recruitment strategies, such as convenience samples of various kinds (e.g., newspaper advertisements, clinical settings, health insurance panels, special professions, and so forth ).

Second, the recruitment process of BASE was continuously monitored to produce a sample that is perfectly stratified by age and gender at the level of the intensive data protocol at first occasion. Stratification has two interrelated main advantages over the necessarily skewed (e.g., age) and unbalanced (e.g., gender) distributions resulting from representative sampling schemes: (a) It produces equally reliable estimates of population 
parameters across all levels of the age variable and in both genders, and (b) it greatly enhances the likelihood of detecting interactions of age, gender, or both with other variables (cf. McClelland \& Judd, 1993).

Third, BASE is characterized by a multi- and interdisciplinary approach and includes information collected by four distinct but closely cooperating research units: internal medicine-geriatrics, psychiatry, psychology, and sociology-economics. The present study takes advantage of this multidisciplinary nature of the data set. For instance, interindividual differences in intellectual functioning are linked to life history information gathered by the sociological research unit (e.g., social class and occupational prestige) and to biological information obtained by medical researchers (e.g., computerized tomography [CT] scan of the brain ).

\section{The Cognitive Battery of BASE}

The cognitive battery of the psychology research unit of BASE consists of 14 tests assessing individual differences in five intellectual abilities: perceptual speed, reasoning, memory, knowledge, and fluency. The measurement properties and procedural aspects of the battery have been described in detail elsewhere (Lindenberger et al., 1993). With respect to measurement theory, the battery is rooted in the psychometric tradition of identifying stable dimensions of individual differences in intelligent behavior (Carroll, 1993). Specifically, the construction of the battery was informed by the two-component model of intelligence (P. B. Baltes, 1987, 1993; cf. P. B. Baltes et al., in press), which is closely related to the Cattell-Horn theory of fluid and crystallized intelligence (Gf-Gc theory; Cattell, 1971; Horn, 1982, 1989; for a comparison of the two approaches, see P. B. Baltes et al., in press). According to the two-component model, perceptual speed, reasoning, and memory represent the "mechanics" of cognition, or the functional architecture of the brain at the time of assessment (e.g., the broad fluid domain in GfGc theory, or "intellectual power" according to Hebb, 1949). In contrast, knowledge and fluency were chosen to primarily represent the pragmatics of cognition, or individual differences in acquired, culturally relevant bodies of knowledge (e.g., the broad crystallized domain in Gf-Gc theory, or "intellectual products" according to Hebb, 1949).

Both for measurement and theoretical reasons, the two-component model does not assume that individual differences in mechanic and pragmatic intellectual abilities are orthogonal to each other. For instance, the acquisition and expression of pragmatic knowledge are assumed to depend on the mechanics of the mind. A good example in this regard are individual differences in verbal fluency, which are not a pure expression of differences in semantic knowledge (e.g., the pragmatics) but also reflect individual differences in speed and ease of information access (e.g., the mechanics; see Salthouse, 1993). Thus, instead of positing a dichotomy, we propose that a main benefit of the two-component model in the context of this and other studies accrues from being able to arrange the five abilities on an empirical continuum of mechanic versus pragmatic influence to derive and test predictions regarding their differential relations to other constructs. In the present context, two such predictions are of major importance. First, we expect that the age relations of the three mechanic abilities are more negative than the age relations of the two pragmatic abilities. Second, we expect that abilities in the mechanic domain are more closely related to individual differences in markers of current brain status, such as vision and hearing, and less closely related to markers of sociocultural differences than abilities in the pragmatic domain. Both predictions emanate from past theorizing and research but have rarely been tested in a large sample of old and very old individuals.

\section{Overview}

In the following, we first provide indispensable information about the sample, the procedures, and the central variables of this study (for more detailed information about the general design of BASE, P. B. Baltes et al., 1996; see P. B. Baltes \& Smith, 1997). After that, the results of the study are organized around four main themes: (a) the age gradients of the five different intellectual abilities measured in this study; (b) the psychometric structure of individual differences in intellectual functioning; (c) the search for age-based differences in interindividual variability (i.e., across-subjects diversity) and intraindividual variability (i.e., within-subject dispersion); and (d) the correlates of old-age intelligence (e.g., the link between general differences in intellectual functioning to sociocultural and biological systems of influence, and the question whether mechanic and pragmatic intellectual abilities are differentially related to sociocultural and biological systems of influence).

Occasionally, we report additional analyses controlling for or investigating the effects of certain variables, most notably gender and dementia diagnosis. In terms of methods, most of the primary analyses are based on one-variable indicators (e.g., years of education) or unit-weighted composites of multiple indicators (e.g., perceptual speed as the average of the $z$ transforms of the three perceptual speed tests). However, we occasionally complement these analyses with structural modeling techniques, such as confirmatory factor analysis or latent regression, to test and illustrate hypotheses regarding the structural properties of this data set or to better control for differences in reliability between competing sets of predictor variables. Unless stated differently, alpha levels were set to .01 .

\section{Method}

\section{Sample}

The data presented in this article refer to alf individuals who completed the 14-session intensive data protocol of the first measurement occasion of BASE ( $N=516$; age range $=70-103$ years, mean age $=84.9$ years, and $S D=8.7$ years). This sample is stratified by age and gender, resulting in 43 men and 43 women in each of six different age brackets (70-74, 75-79, 80-84, 85-89, 90-94, and 95+ years; cf. P. B. Baltes \& Smith, 1997; Nuthmann \& Wahl, 1996).

Study design and sample selectivity. The samples of BASE originate from a random draw of addresses from the general registry of Berlin (West). To obtain a sample of 516 individuals stratified by age and gender at the intensive protocol level, a much larger number of addresses had to be drawn from the general registry (P. B. Baltes \& Smith, 1997; Lindenberger et al., 1996, in press). Specifically, the study design of the first measurement occasion of BASE consists of a hierarchical sequence of four levels of participation with increasing numbers of vari- 
ables but decreasing numbers of participants at each consecutive level: (a) the verified parent sample $(N=1,908)$, with basic information regarding age, gender, marital status, living conditions (e.g., independent or institutionalized), and mortality; (b) the short-contact sample ( $N=$ $1,264)$, with additional observational and questionnaire information (e.g., subjective physical and mental health and observed signs for dementia and severe sensory problems); (c) the intake assessment sample $(N=928)$, with a variety of measures from all four disciplines, including the short form of the Mini-Mental State Exarnination (MMSE; Folstein, Folstein, \& McHugh, 1975); and the intensive protocol sample $(N=516)$ with its 14 sessions of in-depth assessments.

As reported in detail elsewhere (P. B. Baltes \& Smith, 1997; for full detail, see Lindenberger et al., 1996, in press), variables measured at earlier (i.e., low-intensity) participation levels were moderately to highly predictive of interindividual differences in central constructs of the intensive data protocol. For this reason, it was possible to project the consequences of selection effects throughout all levels of participation onto intensive protocol constructs by using a linear regression approach (i.e., the Pearson-Lawley selection formulas). With respect to means, these projections indicate that the intensive protocol sample $(N=516)$ has a positive selection bias in all domains of functioning analyzed so far, such as somatic health, activities of daily living, sensory-sensorimotor and intellectual functioning, social network size, and various personality dimensions such as openness to experience. The magnitude of these selectivity effects was largest for general intelligence but never exceeded half a standard deviation. Moreover, with one exception, selectivity effects did not interact with age or gender. The exception was dementia prevalence, in which the positive selection bias (e.g., the degree to which dementia prevalence was underestimated) was largest in the very old segment of the population (i.e., age $95+$ ).

Most important in the present context is that the analysis of selectivity effects did not provide any strong evidence in favor of a distortion of variances or covariances as a consequence of sample attrition. Specifically, a series of orthogonal contrasts revealed that the variances and covariances observed for continuing participants did not differ much, if at all, from the variances and covariances observed for participants who did not reach the next level of participation (Lindenberger et al., 1996, in press). These results suggest that the structural relations among variables, which figure prominently in this article, were not much influenced by sample selectivity.

Dementia prevalence. Of the 516 participants in the intensive data protocol, 109 (i.e., $21 \%$ ) received a clinical diagnosis of dementia according to Diagnostic and Statistical Manual of Mental Disorders (DSM-III-R; 3rd ed., rev; American Psychiatric Association [APA], 1987) criteria (cf. Helmchen et al., 1996; very mild to mild, $n=37$; moderate, $n=33$; and severe, $n=39$ ). Using standard clinical interview and assessment procedures, an experienced clinician who was unaware of the results of cognitive and neuropsychological assessments made the diagnosis. Dementia prevalence was related to age (point-biserial correlation, $r=.36$ ). Women were somewhat more likely to be diagnosed as demented than men $(25 \%$ vs. $17 \%)$, but the difference was not statistically reliable at the .01 level, $\chi^{2}(1, N=516)=4.22, p=$ .04. After statistically controlling for individual differences in years of education, the association between gender and dementia diagnosis disappeared completely, $\chi^{2}(1, N=516)=1.78, p=.18$.

In this article, we focus mainly on the full intensive protocol sample $(N=516)$; that is, on the sample that includes individuals with a clinical diagnosis of dementia. In addition, we also report results obtained after excluding individuals with a clinical diagnosis of dementia $(n=407$; mean age $=83.3$ years ).

Our emphasis on the full, rather than the reduced, sample has two reasons. First, it can be argued, from a radically descriptive point of view, that the age-based increase in dementia prevalence forms an integral part of aging as a population process. Therefore, if the goal is to describe changes in population parameters, the a priori exclusion of individuals who supposedly suffer from some form of dementia leads to a less generalizable picture of age differences in intellectual functioning in old and very old age than results that are based on an age-stratified random sample of the total population.

The second reason is more methodological in kind. It is commonly assumed that the validity and reliability of a clinical diagnosis of dementia, especially in the very mild-to-moderate range and among the very old, are far from perfect. For this reason, an a priori exclusion of participants with a dementia diagnosis would have the unwanted consequence that subsequent analyses are conditionalized on an assessment that most likely is less reliable than many of the measures used thereafter.

\section{Procedure}

Overview. In the following, we restrict the description of measures and procedures to variables that are of primary relevance in the context of this article: (a) intellectual functioning as assessed by a battery of 14 cognitive tests (Lindenberger et al., 1993); (b) sensory and sensorimotor functioning as assessed by clinical measures of auditory acuity, balancegait, and visual acuity tests; (c) other medical variables, most notably an index of brain atrophy, but also general somatic morbidity and medication; (d) sociological indicators of sociostructural-biographical differences (e.g., household income, occupational prestige, social class, and years of education). If not stated otherwise, the remaining variables were either made available by the general registry (e.g., chronological age, gender, and marital status) or they were assessed during the interdisciplinary first-contact session (for more information, see P. B. Baltes \& Smith, 1997).

Cognitive assessment. The cognitive test battery comprised 14 tests measuring five intellectual abilities: (a) perceptual speed (measured by Digit Letter, Digit Symbol Substitution, and Identical Pictures); (b) reasoning (Figural Analogies, Letter Series, and Practical Problems); (c) memory (e.g., short-term acquisition and retrieval; Activity Recall, Memory for Text, and Paired Associates); (d) knowledge (Practical Knowledge, Spot-a-Word, and Vocabulary); and (e) fluency (Animals and Letter $S$ ). A detailed description of the tests has been provided elsewhere (Lindenberger et al,, 1993). The internal consistencies, interrater agreements, and confirmatory factor loadings of the tests for the present sample (i.e., $N=516$ ) are reported in Table 1. Reliability estimates (i.e., internal consistencies, interrater agreements, or both) were satisfactory for all tests of the battery. In accordance with earlier analyses based on a subsample $(N=156)$ of the present data set (Lindenberger \& Baltes, 1994b), the correlational structure of the cognitive battery was well described by a hierarchical factor model with five firstorder factors representing the five different intellectual abilities and a single second-order factor representing general intelligence (see Figure 1; for details, see below).

Cognitive testing was assisted by a Macintosh SE/30 equipped with a touch-sensitive screen. With respect to tests related to reasoning and knowledge, items were ordered by ascending order of difficulty, and lesting was terminated when participants made a certain number of consecutive failures ( three in the case of Figural Analogies, Letter Series, Practical Problems, and Spot-a-Word and six in the case of Vocabulary). Item-difficulty information had been obtained in a separate study (Lindenberger et al., 1990). With the exception of the Digit Letter and the Digit Symbol Substitution tests, instructions were presented in large fonts on the computer screen. In case of the Digit Letter and the Digit Symbol, instructions were presented in large fonts on a piece of paper.

Testing took place at the residence of the participants. Tests were administered in the following order: Digit Symbol Substitution, Spot-aWord, Memory for Text, Figural Analogies, Letter $S$, Vocabulary, Practical Problems, Digit Symbol Substitution, Activity Recall, Identical Pictures, Paired Associates, Animals, Letter Series, and Practical Knowl- 
Table 1

Internal Consistencies, Interrater or Intercoder Agreements, and Factor Loadings of the 14 Cognitive Tests

\begin{tabular}{|c|c|c|c|c|}
\hline Ability/Test ${ }^{a}$ & $\alpha^{\mathrm{b}}$ & $r^{c}$ & $\tau_{c}^{d}$ & $\beta^{e}$ \\
\hline \multicolumn{5}{|l|}{ Reasoning } \\
\hline Figural Analogies & .90 & & & .76 \\
\hline Letter Series & .86 & & & .79 \\
\hline Practical Problems & .84 & & & .82 \\
\hline \multicolumn{5}{|l|}{ Memory } \\
\hline Paired Associates & .87 & .99 & .94 & .72 \\
\hline Activity Recall & .61 & .91 & .80 & .82 \\
\hline Memory for Text & .57 & .96 & .86 & .66 \\
\hline \multicolumn{5}{|l|}{ Perceptual Speed } \\
\hline Identical Pictures & .90 & & & \\
\hline Digit Letter Test & .96 & 1.0 & 1.0 & \\
\hline Digit Symbol Substitution & & 1.0 & .99 & .92 \\
\hline \multicolumn{5}{|l|}{ Knowledge } \\
\hline Spot-a-Word & .92 & & & \\
\hline Vocabulary & .82 & .96 & .85 & .8 \\
\hline Practical knowledge & .82 & .95 & .84 & 8 \\
\hline \multicolumn{5}{|l|}{ Fluency } \\
\hline Categories (Animals) & & .99 & .94 & .8 \\
\hline Word Beginnings (Letter $S$ ) & & .99 & .94 & \\
\hline
\end{tabular}

${ }^{2}$ Detailed descriptions of the tests are provided in Lindenberger et al. (1993). 'Cronbach's alpha. Incorrect responses and performance on items that were not attempted were coded as zero. ${ }^{\mathrm{c}}$ Intercoder reliability (Pearson's $r$ ); not present for tests with computerized response entry. "Intercoder reliability (Kendall's $\tau_{\mathrm{c}}$ ); not present for tests with computerized response entry. ${ }^{e}$ Factor loadings (i.e., path coefficients) for the final measurement model (i.e., Model MM2 in Table 4). $\mathbf{M M}=$ measurement model.

edge. In $81 \%$ of the cases, the entire test battery was administered in a single session. In almost all remaining instances, testing was divided into two sessions. In that case, the first session ended with Activity Recall, the second session began with Identical Pictures, and all tests were administered in the original sequence. Participants who could not work on the computerized version of the battery because of very poor vision or blindness were administered a shortened auditory version of the battery.

Overall, 494 of the total of 7,224 attainable data points (i.e., 516 people $\times 14$ tests), or $6.8 \%$, were missing from the cognitive data set. Specifically, between $9 \%$ and $15 \%$ of the data were missing for the three reasoning tests, the three perceptual speed tests, and the Spot-a-Word test; for the remaining tests, "missingness" was below $1 \%$. There were two main reasons for missing data. First, 57 research participants, or $11 \%$ of the sample, had very poor vision so that computerized testing was totally or partly impossible. This condition primarily affected the administration of the reasoning and perceptual speed tests as well as the administration of the Spot-a-Word test. Second, some of the research participants were intellectually unable to understand the instructions for some of the tests (e.g., Figural Analogies and Letter Series).

Unless stated differently, the data reported in this article refer to the Persons $\times$ Variables matrix after replacement of missing data through estimates based on linear regression. Missing data were estimated within each of the five intellectual abilities; that is, without the use of information based on tests of the remaining four intellectual abilities. Specifically, missingness information (i.e., whether tests of the given ability were missing) was explicitly coded as a dummy variable and was entered, in addition to the actual test scores, which were set to the sample mean when missing, into the linear regression equation (cf. Rovine \& Delaney, 1990). After that, missing values were substituted by scores predicted on the basis of this linear regression. Note that replacement of missing values through regression estimates of this kind is less likely to result in distortions of the data structure than listwise deletion (Beale \& Little, 1975). Nevertheless, we routinely checked whether analyses based on listwise deletion differed from analyses with estimated data and obtained virtually identical results.

\section{Sensory and Sensorimotor Variables}

Auditory acuity (i.e., hearing). Measures related to auditory acuity were assessed with a Bosch ST-20-1 pure-tone audiometer with headphones. Thresholds were measured separately for the right and left ears at eight different frequencies. Sixteen percent of the individuals in the BASE sample had hearing aids. For technical reasons, thresholds were assessed without hearing aids only. Testing started with the better ear; for participants who did not know which ear was their better one, it started with the right ear. Within ears, frequencies were tested in the following order: $1.00,2.00,3.00,4.00,6.00,8.00,0.50$, and $0.25 \mathrm{kHz}$. The loudness of the pure tone was continuously increased until research participants signaled that they were able to hear the tone. Hearing thresholds were measured in decibel units on a continuous scale ranging from 0 (high hearing ability) to 100 (low hearing ability). Research participants who were unable to hear a given tone at $100 \mathrm{~dB}$ were assigned a score of 100 (i.e., the extreme end of the scale).

In keeping with earlier articles on select facets of this data set (Lindenberger \& Baltes, 1994b), the composite of auditory acuity, or hearing ability, was based on the inverted unit-weighted composite of three aggregates: (a) the standardized mean of lower frequencies thresholds in the right ear (i.e., $0.25,0.50,1.00,2.00,3.00$, and $4.00 \mathrm{kHz}$ ), (b) the standardized mean of lower frequencies thresholds in the left ear (i.e., $0.25,0.50,1.00,2.00,3.00$, and $4.00 \mathrm{kHz}$ ), and (c) the standardized mean of the log transforms of the two highest frequencies across both ears (i.e., 6.00 and $8.00 \mathrm{kHz}$ ). High-frequency thresholds were $\log$ transformed because skewness was greater than one in all four variables, reflecting the fact that a substantial number of participants were unable to hear the tone at $100 \mathrm{~dB}$. The three aggregates used to compute the hearing composite were highly correlated with each other (right-ear lower frequencies with left-ear lower frequencies, $r=.76$; right-ear lower frequencies with high frequencies, $r=.70$; and left-ear lower frequencies with high frequencies, $r=.70$ ).

Balance-gait. Balance-gait was measured with two clinical assessments of balance and gait: the Romberg Stance and the Turn 360 task (cf. Marsiske et al., 1996; Tinetti, 1986). In the Romberg Stance task, participants stood upright for about $1 \mathrm{~min}$, with legs as close together as possible, arms extended in front of the body, palms turned up, and eyes closed. Performance was scored by a physician on a 6-point scale ranging from 1 (not able to stand upright at all) to 6 (no swaying). In the Turn 360 task, participants were asked to perform a full turn around their body axis as fast as they could without risking a fall. The score corresponded to the number of steps needed to finish the circle. The correlation between the two scores was -.63 . Scores on the Turn 360 task were inverted, and both scores were standardized and combined to form the balance-gait composite.

Visual acuity (i.e., vision). Visual acuity was measured in Snellen decimal units at two different distances with two different standard reading tables (Geigy Pharmaceuticals, 1977). Distance visual acuity was assessed binocularly with a reading table presented at a standard distance of $2.5 \mathrm{~m}$ to the participant (cf. Marsiske \& Klumb, 1997). Close visual acuity was measured separately for the left and the right eye with a reading table presented at reading distance. All three measurements were taken without and with the best optical correction (i.e., glasses) available to the participant. Ninety-two percent of the participants had at least one pair of glasses. The analyses reported in this article are based on the better values, which in most cases referred to corrected vision. As argued elsewhere (P. B. Baltes \& Lindenberger, 


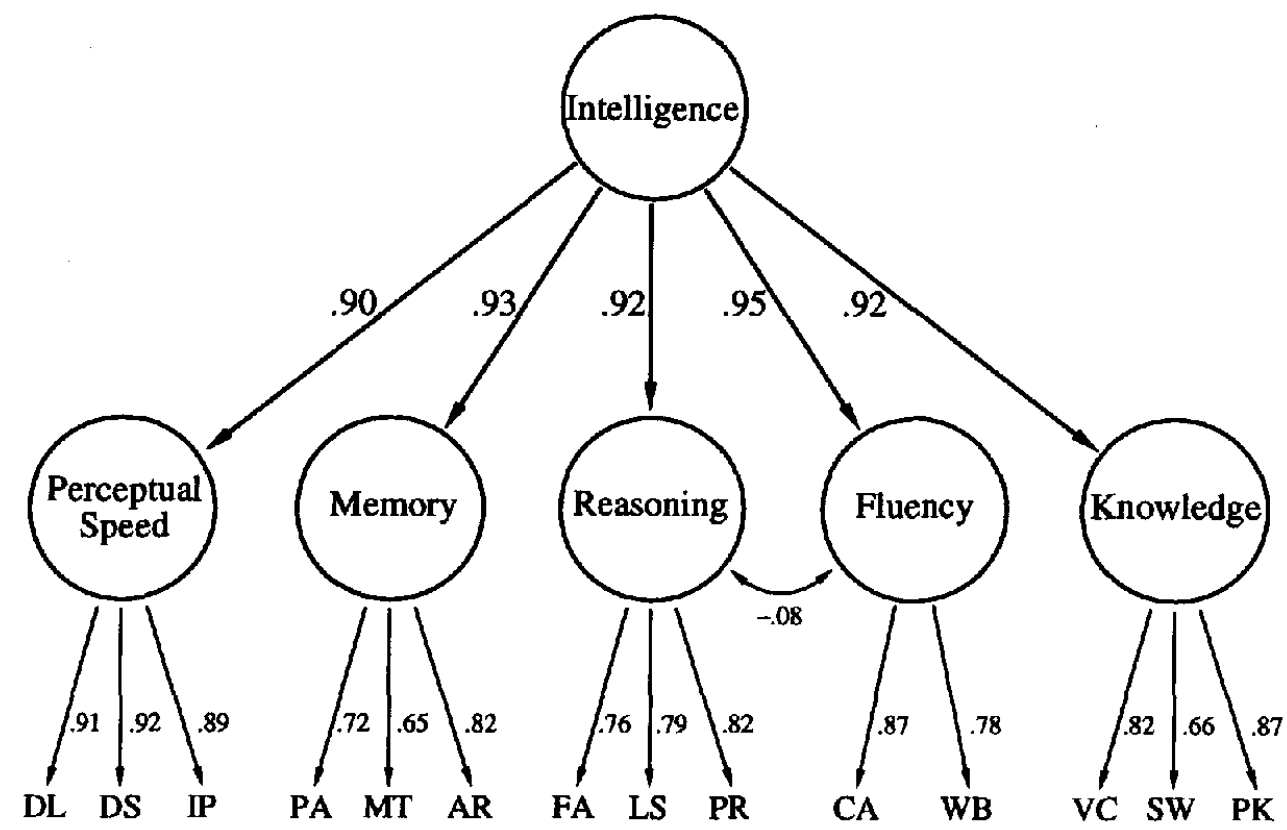

Figure 1. A hierarchical model of individual differences in intellectual functioning in old and very old age. The figure corresponds to model HM2 in Table $4, \chi^{2}(69, N=516)=146.29$, nonnormed fit index $=.981$, cumulative fit index $=.985 . \mathrm{DL}=$ Digit Letter; $\mathrm{DS}=$ Digit Symbol; IP $=$ Identical Pictures; PA = Paired Associates; MT = Memory for Text; AR = Activity Recall; FA = Figural Analogies; LS = Letter Series; PR = Practical Reasoning; $\mathrm{CA}=$ Categories; $\mathrm{WB}=$ Word Beginnings; $\mathrm{VC}=$ Vocabulary; $\mathrm{SW}=$ Spot-a-Word; PK = Practical Knowledge; $\mathbf{H M}=$ hierarchical model.

1997; Lindenberger \& Baltes, 1994b), corrective devices (e.g., glasses) filter out at least some of the peripheral variance (e.g., variance due to individual differences in the refractory properties of the lens), thereby allowing for a more direct assessment of the portion of sensory loss that is central-neuronal in nature. The composite score was based on the unit-weighted mean of close visual acuity (averaged over the left and right eye) and distance visual acuity $(r=.49)$.

\section{Medical-Biological Variables}

Brain atrophy index. As part of the medical exam of BASE (Helmchen et al., 1996; Steinhagen-Thiessen \& Borchelt, 1996), a CT scan was performed at two different layers of the brain. Both internal (e.g., ventricle size) and external atrophy (e.g., the distance between the brain and the skull) were assessed and were subsequently rated by an experienced clinician on a 4-point scale. The clinician was unaware of all other characteristics of the research participants including their age. The present score is based on the unit-weighted composite of the indexes of inner and outer atrophy, which were moderately intercorrelated ( $r=.54$ ). Primarily for organizational reasons, the CT scan was administered to only 254 of the 516 research participants (mean age $=$ 81.5 years, age range $=70-99$ years, $S D=7.7$ ). Of these 254,143 were men, and 24 had received a clinical diagnosis of dementia. Additional procedural and descriptive information regarding this measure can be found elsewhere (Reischies, Rossius, \& Felsenberg, 1997).

General somatic morbidity. This variable corresponds to the number of distinct clinically relevant diagnoses according to $D S M-I I I-R$ (APA, $1987)$ criteria $(M=8.1, S D=4.0)$. A detailed description of somatic morbidity in BASE is provided by Steinhagen-Thiessen and Borchelt (1996).

Medication. This variable refers to the number of clinically relevant prescribed medications $(M=3.6, S D=2.7)$. The validity of this measure is described in more detail in Linden, Gilberg. Horgas, and Steinhagen-Thiessen (1996).

\section{Sociological and Life History Variables}

Income. This variable represents the amount of net income in Deutsche Mark per month per capita on a 5-point scale: 1 (less than $1,000), 2(1,000-1,399), 3(1,400-1,799), 4(1,800-2,199)$, to 5 (2,200 and more).' The variable had a mean of 3.44 and a standard deviation of 1.22. Detailed information regarding the income distribution in this sample can be found elsewhere (Mayer \& Wagner, 1996; Wagner, Motel, Spieß, \& Wagner, 1996).

Occupational prestige. This scale is based on a standard rating scale of occupational prestige in Germany (Wegener, 1985; cf. Mayer \& Wagner, 1993, 1996). Ratings refer to the prestige of the participants' last occupation before retirement. About $4 \%$ of the sample was never part of the labor force. In the case of these individuals, the prestige of the last occupation of the spouse (former spouse if widowed) was used as a substitute. Prestige scores varied from 22.7 to $186.8(M=79.6$, $S D=32.2$ ) and were slightly skewed (skewness $=1.28$ ). To reduce skewness, a log transform of the original scale was used in the following analyses $(M=1.87, S D=0.16$, skewness $=0.40)$.

Social class index. Participants were arranged on a continuum of social stratification, ranging from lower class ( $7 \%$ of the sample), lower middle class $(20 \%)$, middle class $(31 \%)$, upper middle class $(30 \%)$,

\footnotetext{
1 This same scale for approximate U. S. dollar amounts is as follows: 1 (less than $\$ 600), 2(\$ 600-\$ 819), 3(\$ 820-\$ 1,059), 4(\$ 1,060-$ $\$ 1,299)$, to $5(\$ 1,300$ and more $)$.
} 
to high-middle class ( $11 \%$; cf. Mayer \& Wagner, 1996). The term upper class was avoided because none of the participants belonged to the social elite (e.g., top managers, entrepreneurs of large firms, high-ranking politicians, and so forth).

Years of education. This variable represents the number of years spent in formal educational settings. In addition to the number of years spent in elementary school and the different types of high school in Germany (Hauptschule, Realschule, and Gymnasium), it also includes formal professional (e.g., apprenticeships) and academic (e.g., university) training. On average, participants in this sample had 10.8 years of education $(S D=2.3)$.

\section{Results}

\section{Age Gradients of Intellectual Abilities in Old and Very Old Age}

Overview. Figure 2 shows the age relations of the five intellectual abilities in a T-score metric $(M=50, S D=10)$. The findings replicate and extend earlier reports based on the initial subsample of 156 individuals (Lindenberger \& Baltes, 1994b; Lindenberger et al., 1993). The linear age relations of the unitweighted composites ranged from - .41 for knowledge to -.59 for perceptual speed; for latent ability constructs, they ranged from -.49 (knowledge) to -.61 (perceptual speed). The magnitude of age relations was somewhat less pronounced when individuals with a clinical diagnosis were excluded from the analysis ( see Table 2, and the thinner regression lines of Figure 2). Quadratic age trends did not differ significantly from zero (perceptual speed, $r=.03$; reasoning, $r=.09$; memory, $r=$ .00 ; knowledge, $r=.00$; and fluency, $r=.00$; all $p \mathrm{~s}>.01$ ), suggesting that relations between performance level and age were well captured by the linear age gradients shown in Figure 2.

A cautionary note on the interpretation of cross-sectional age gradients in old and very old age. Given the great extent and selective nature of mortality in old and very old age (Rudinger \& Rietz, 1995; Siegler \& Botwinick, 1979), and the possible existence of generational differences and other cohort effects (P. B. Baltes, Reese, \& Nesselroade, 1988; Schaie, 1996), we caution that the cross-sectional age gradients reported in this article must not be understood as unbiased approximations of average intraindividual longitudinal change. Most likely, selective mortality exerts a strong effect on cross-sectional age comparisons in old and very old age. According to current population estimates for Germany, only about $20 \%$ of the 70 -year-old participants represented in Figure 2 will actually reach age 90 . In other words, the regression lines connect about $74 \%$ of the age-70 birth cohorts with about $13 \%$ of the age- 90 birth cohorts. The selective nature of the mortality process (i.e., its correlation with the phenomena under study) implies that individuals with relatively low intellectual status and pronounced intellectual decline are increasingly less likely to contribute to the regression estimate as one moves along the age axis compared with individuals with relatively high intellectual status and little decline. For this reason, cross-sectional age gradients in this age range may have a "natural" bias in the positive direction and may underestimate, rather than overestimate, the average extent of intraindividual longitudinal decline in old and very old age. For instance, the linear shape of the cross-sectional age gradients observed in this study does not exclude the possibility that the modal shape of intraindividual change is negatively accelerated, rather than linear. Additional longitudinal, cohort-sequential, mortalityrelated, and life history information is needed to decompose the observed age gradients into their constituents (e.g., Keiding, 1991; Kruse, Lindenberger, \& Baltes, 1993; McArdle \& Woodcock, in press).

Ability-specific differences in the magnitude of age-based decrements: Mechanics versus pragmatics. Table 2 reports the linear age relations of the five intellectual abilities. As expected, negative age relations were more pronounced for the three mechanic than for the two pragmatic abilities (for unit-weighted composites, $z=4.98, p<.01$; for latent ability constructs, $z$ $=5.34, p<.01) .^{2}$ Analyses with the reduced sample (i.e., after exclusion of demented participants) led to analogous results: unit-weighted composites, $z=4.33, p<.01$; latent ability constructs, $z=4.80, p<.01$.

Within the three mechanic abilities, the age relation of perceptual speed $(r=-.59)$ was more pronounced than the average age relations of reasoning $(r=-.51)$ and memory $(r=-.49$, $z=3.60, p<.01$ ). In contrast, the age gradients of the two more pragmatic abilities did not differ significantly from each other (knowledge, $r=-.41$; fluency, $r=-.46, z=1.45, p>$ $.10)$. Analyses without the demented and analyses based on latent ability constructs provided the same result.

With respect to cross-sectional age gradients, then, we conclude that the distinction between mechanic (broad fluid) and pragmatic (broad crystallized) intellectual abilities extends into old and very ald age. However, compared with earlier periods of the life span, the distinction in age trajectories appears to be less pronounced. Specifically, earlier differences in directionality (i.e., stability-decrements vs. stability-increments ) are converted into different degrees of linear decrement. In this context, it is important to note that the three tests of knowledge were administered without any external constraints on testing time and that instructions, if necessary, were repeated to make sure that participants knew what they were supposed to do. Thus, it is difficult to argue that the negative age gradient for knowledge primarily reflects the operation of age-associated but abilityextraneous performance factors.

Examination of gender differences in level and age relations of intellectual functioning. Hierarchical regression analyses were computed to examine the possible existence of gender differences in the level and the age relations of intellectual functioning for each of the five intellectual abilities. Because of stratification, age and gender were orthogonal in this sample (average age for men $=84.7$ years; average age for women $=$ 85.1 years; and correlation between gender and age, $r=.02$, $n s)$. Therefore, age, gender, and the Age $\times$ Gender interaction,

\footnotetext{
${ }^{2}$ Throughout this article, differences between (sets of) correlated correlation coefficients were tested for statistical significance with the formulas proposed by Meng, Rosenthal, and Rubin ( 1992). For instance, differences in the age relations of mechanic and pragmatic abilities were tested with Formula 8 of Meng et al. This formula allows researchers to specify a contrast to test whether one set of variables (e.g., mechanic abilities) is more highly related to a criterion variable (e.g., age) than another set of variables (e.g., pragmatic abilities).
} 


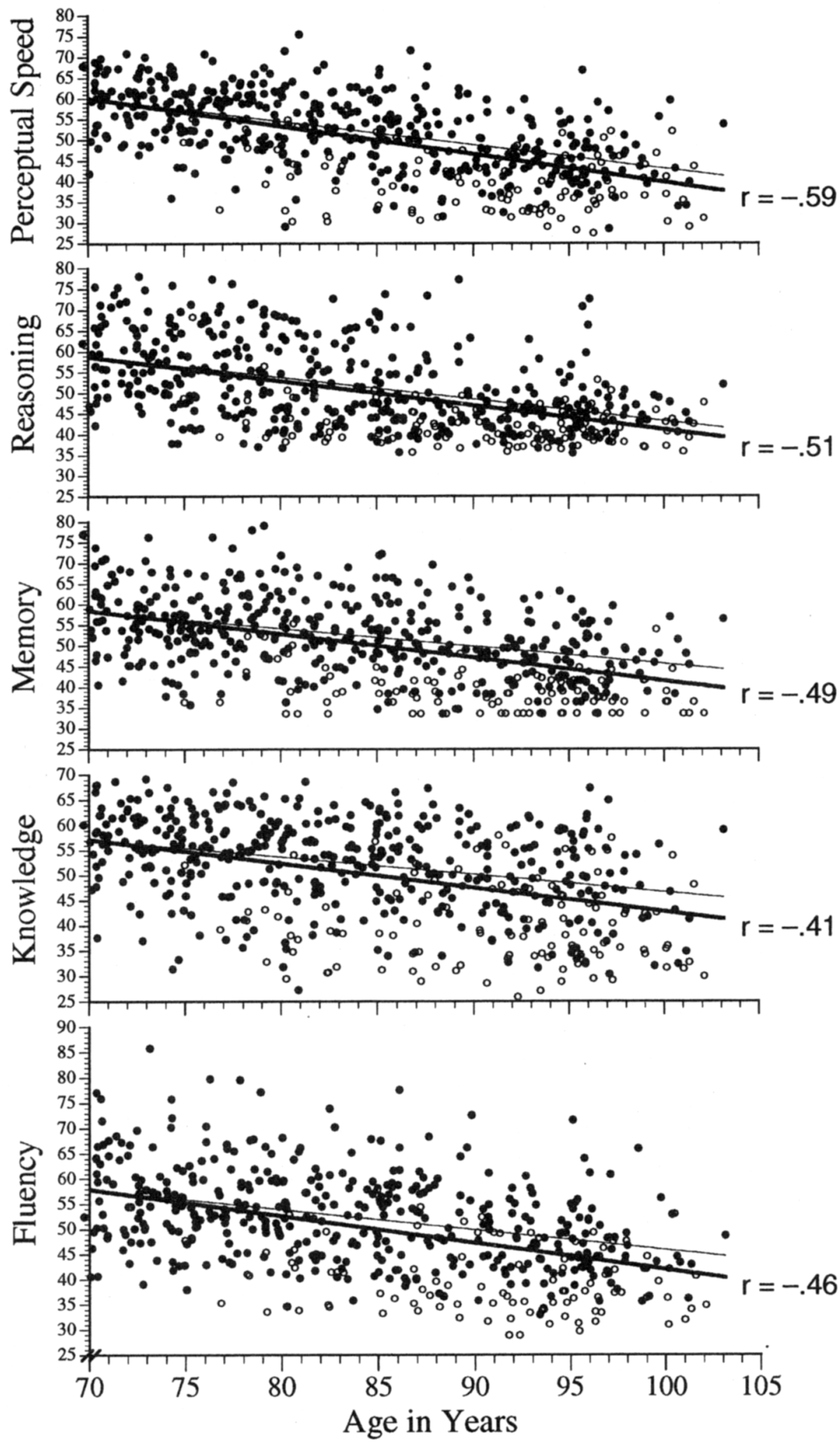

Figure 2. Cross-sectional gradients for five intellectual abilities. Ability scores are based on unit-weighted composites of the corresponding tests and are scaled in a T-score metric $(M=50, S D=10)$. Individuals without a diagnosis of dementia are represented by filled dots, and individuals diagnosed as demented are represented by unfilled dots. The thinner lines refer to values obtained when the 109 individuals diagnosed as demented were not included in the analysis. 
Table 2

Correlations Between Intellectual Abilities and Age (70-103 Years)

\begin{tabular}{|c|c|c|}
\hline Ability & $\begin{array}{c}\text { Total } \\
\text { sample } \\
(N=516)\end{array}$ & $\begin{array}{l}\text { Without individuals } \\
\text { with dementia diagnosis } \\
(n=407)\end{array}$ \\
\hline \multicolumn{3}{|c|}{ Mechanics (broad fluid) } \\
\hline $\begin{array}{l}\text { Perceptual speed } \\
\text { Reasoning } \\
\text { Memory }\end{array}$ & $\begin{array}{l}-.59(-.61) \\
-.51(-.56) \\
-.49(-.56)\end{array}$ & $\begin{array}{l}-.54(-.58) \\
-.44(-.49) \\
-.39(-.47)\end{array}$ \\
\hline \multicolumn{3}{|c|}{ Pragmatics (broad crystallized) } \\
\hline $\begin{array}{l}\text { Knowledge } \\
\text { Fluency }\end{array}$ & $\begin{array}{l}-.41(-.49) \\
-.46(-.53)\end{array}$ & $\begin{array}{l}-.33(-.41) \\
-.40(-.45)\end{array}$ \\
\hline
\end{tabular}

Note. Values without parentheses refer to unit-weighted composites of the indicators and correspond directly to Figure 2. Values in parentheses are based on a latent model positing five intercorrelated intellectual abilities (i.e., model MM2 in Table 4) with age as a correlate at the latent level. $\mathbf{M M}=$ measurement model

which was orthogonalized with respect to the two main effects, were entered simultaneously into the linear regression equation.

In addition to main effects of age, which, reflecting the orthogonality of the predictors, were identical to those reported before, we observed two main effects of gender: one for reasoning and the other for knowledge. In both cases, men had significantly higher scores than women: reasoning, $\beta=-.13, t(1)=$ $-3.37, p<.002$; knowledge, $\beta=-.15, t(1)=-3.68, p<$ $.002 ; p$ values are Bonferroni adjusted, that is, .01/5. When expressed in standard deviation units (i.e., $\left[M_{\text {men }}-M_{\text {women }}\right] /$ $S D_{\text {pooldd }}$ ), the effect size of the male advantage was .28 for reasoning and .31 for knowledge. None of the remaining effects was significant. Specifically, there were no indications that age gradients differed significantly as a function of gender.

A possible reason for the observed male advantage refers to the existence of historically stable gender-linked inequalities in societal opportunity structures such as access to formal education. On average, men had received more education than women (men: $M=11.3$ years, $S D=2.5$; women: $M=10.2$ years, $S D$ $=2.0), t(1)=-5.62, p<.01$. In accordance with the socialinequality interpretation, gender differences in reasoning and knowledge were no longer significant after statistically controlling for individual differences in education: reasoning, $\beta=$ $-.05, t(1)=-1.48, p=.14$; knowledge, $\beta=-.06, t(1)=$ $-1.66, p=.10$. However, we now noticed a significant female advantage for memory: $\beta=.12, t(1)=3.13, p<.002$. Possibly, this female advantage had been masked by gender-linked individual differences in years of education in the original analysis. Note that the existence of a small but reliable episodic-memory advantage for women is consistent with findings from several other large-scale studies on memory functioning during adulthood and old age (cf. Herlitz, Nilsson, \& Bäckman, in press).

\section{The Structure of Intellectual Abilities in Old and Very Old Age}

We now turn to the structural properties of intellectual functioning in old and very old age. First, we inspect the intercorrela- tions of the five intellectual abilities. Second, we propose a structural model to capture the structure of old-age intelligence in a more formal manner.

Intercorrelations of intellectual abilities. Table 3 reports the intercorrelations among the five intellectual abilities. Correlations were high and uniform throughout all five abilities. For instance, at the level of unit-weighted composites, the median correlation among the five intellectual abilities was $r=.70$, the lowest correlation was $r=.63$, and the highest correlation was $r=.73$. When performing an exploratory factor analysis with principal-components extraction over the five unit-weighted ability scores, the first unrotated factor accounted for $75 \%$ of the total variance. Finally, at the level of latent constructs (e.g., after correcting for unreliability), the median correlation was $r$ $=.85$, the lowest correlation was $r=.77$, and the highest correlation was $r=.89$.

The magnitude of these intercorrelations is above the range that is commonly observed during earlier phases of the adult life span (cf. Carroll, 1993). For the purpose of comparison, a recent study from our own laboratory is particularly useful. In that study (P. B. Baltes \& Lindenberger, 1997), we administered the identical battery of cognitive tests to a heterogeneous sample of 171 adults aged 25-69 years. Using unit-weighted composites, we determined that the median intercorrelation among the five intellectual abilities was $r=.38$, the lowest correlation was $r=.22$, and the highest correlation was $r=.42$.

In addition to sheer magnitude, another important feature of the correlational structure was its homogeneity. For instance, correlations within mechanic and pragmatic domains were not higher than correlations between the two domains (median correlation between perceptual speed, reasoning, and memory, $r=$ .71; correlation between knowledge and fluency, $r=.70$; and median correlation between the two domains, $r=.70$ ). Thus, in contrast to age relations, the pattern of intercorrelations did not follow the mechanic-pragmatic distinction.

The finding of uniformly high ability intercorrelations extends the results of earlier studies on age differences in ability intercorrelations (P. B. Baltes et al., 1980; Schaie et al., 1989) and gives further support to the dedifferentiation or neointegration hypothesis of old-age intelligence (P. B. Baltes et al., 1980; P. B. Baltes et al., in press; Lienert \& Crott, 1964; Reinert, 1970; cf. Garrett, 1946; Spearman, 1927). From a methodological point of view, however, one may object that the magnitude of ability intercorrelations represents little more than the necessary consequence of the magnitude and uniformity of the age relations of the five abilities (Merz \& Kalveram, 1965; Lindenberger \& Pötter, 1997; Reinert, Baltes, \& Schmidt, 1966). To examine this possibility, we also inspected the age-partialed intercorrelations among the five intellectual abilities (see Table 3 ). Ability intercorrelations were lowered by controlling for age, but they still were of greater magnitude and uniformity than comparable correlations during earlier periods of the adult life span. At the level of unit-weighted composites, the median correlation was $r=.61$, the lowest correlation was $r=.52$, and the highest correlation was $r=.64$. When performing an exploratory factor analysis with principal-components extraction over the five age-partialed ability scores, the first unrotated factor still accounted for $68 \%$ of the total variance. Finally, when 
Table 3

Intercorrelations Among Intellectual Abilities

\begin{tabular}{lccccc}
\hline \multicolumn{1}{c}{ Ability } & 1 & 2 & 3 & 4 & 5 \\
\hline 1. Perceptual speed & - & $.72(.82)$ & $.71(.85)$ & $.71(.83)$ & $.73(.85)$ \\
2. Reasoning & $.60(.73)$ & - & $.64(.80)$ & $.70(.86)$ & $.63(.77)$ \\
3. Memory & $.60(.77)$ & $.52(.71)$ & - & $.66(.84)$ & $.70(.89)$ \\
4. Knowledge & $.64(.77)$ & $.62(.81)$ & $.58(.79)$ & - & $.70(.87)$ \\
5. Fluency & $.64(.79)$ & $.52(.68)$ & $.61(.84)$ & $.63(.83)$ & - \\
\hline
\end{tabular}

Note. $\quad N=516$. First-order correlations are shown above, whereas age-partialed correlations are shown below the main diagonal. Values without parentheses refer to unit-weighted composites, whereas values in parentheses refer to latent factors (i.e., Model MM2 in Table 4; below the main diagonal, the five latent ability factors were regressed on age). $\mathbf{M M}=$ measurement model.

controlling for age at the latent level, we observed a median correlation of $r=.78$

One may also object that the presence of demented individuals who scored low across all tests of the battery also may have boosted the magnitude of ability intercorrelations. To explore this issue, we examined the magnitude of ability intercorrelations after excluding individuals with a clinical diagnosis of dementia $(n=109)$. In the reduced sample $(n=407)$, we observed a median correlation for unit-weighted composites of $r=.61$ before and of $r=.54$ after controlling for individual differences in chronological age (latent level, $r=.79$ vs. $r$ $=.73$ ).

In summary, the presence of strong and uniform age relations and the presence of individuals with a clinical diagnosis of dementia did, in fact, contribute a significant share to the magnitude of ability intercorrelations observed in this sample. However, the magnitude and uniformity of ability intercorrelations remained substantial after controlling for both of these factors and clearly exceeded the range of ability intercorrelations observed in younger age groups of comparable heterogeneity. On the basis of this evidence, we conclude that differences in intellectual functioning in old and very old age show a much greater degree of consistency (homogeneity) across abilities and ability domains than differences in intellectual functioning during earlier periods of the adult life span.

The structure of old-age intelligence: Second-order dedifferentiation. The preceding results suggest that a hierarchical model of intelligence with five first-order intellectual abilities and a single second-order factor of general intelligence is likely to provide a parsimonious and adequate representation of individual differences in this sample. To examine this possibility, we first established a measurement model of the cognitive battery positing the existence of five distinct but intercorrelated intellectual abilities. Then, we tested whether the hypothesized hierarchical model provided an appropriate representation of ability interrelations (cf. Lindenberger \& Baltes, 1994b).

The most important results of ensuing model comparisons are summarized in Table 4. The first measurement model (i.e., Model MM1 in Table 4) had the following specifications: (a) Each of the 14 indicators loaded on one, and only one, of the five factors (i.e., secondary loadings were not permitted); (b) the residual variances of the indicators were freely estimated; (c) all residual covariances were set to zero, reflecting the assumption that correlated measurement error was negligible; and (d) the five factors representing the five different intellectual abilities were allowed to freely intercorrelate. For this model, we obtained $\chi^{2}(67, N=516)=179.78, p<.01$, BentlerBonett nonnormed fit index $(\mathrm{NNFI})=.971$, comparative fit index $(\mathrm{CFI})=.979$, and average off-diagonal standardized residuals $($ AODSR $)=.021$.

After inspecting the residual correlation matrix, two residual covariances of the indicators were allowed to be freely estimated: the residual covariance between Spot-a-Word and Vocabulary and the residual covariance between Digit Letter and Digit Symbol Substitution (cf. Lindenberger et al., 1993). Note that these residual covariances did not cross factor boundaries. Therefore, they did not compromise the five-factor structure of the measurement model. The introduction of these two residual covariance terms led to a significant increment in fit, $\Delta \chi^{2}(2$, $N=516)=40.53, p<.01$. For this modified measurement model (i.e., Model MM2 in Table 4), we obtained $\chi^{2}(65, N=$ $516)=139.25, p<.01, \mathrm{NNFI}=.980, \mathrm{CFI}=.986$, AODSR $=.017$. When expressed in a standardized (i.e., correlational) metric, the residual covariance between Spot-a-Word and Vocabulary was $.31(z=5.26)$, and the residual covariance between Digit Letter and Digit Symbol Substitution was $.27(z=$ $2.74)$. The inspection of the residual correlation matrix did not suggest any further changes to the measurement model. Therefore, this model (i.e., Model MM2 in Table 4) was accepted as the final measurement model.

In a nested comparison, we then tested the hypothesized hierarchical model against this measurement model. The hierarchical model reflected the assumption that the pattern of intercorrelations among the five intellectual abilities is perfectly captured by a single factor at the second-order level. In such a model, the intercorrelations between any given pair of intellectual abilities are reproduced by the multiplication of their loadings on the second-order General factor. A direct comparison revealed that this hierarchical model (i.e., HM1 in Table 4) led to a small but significant reduction in fit as compared with the final measurement model, $\Delta \chi^{2}(5, N=516)=20.85, p<.01$.

An inspection of the residual correlation matrix showed that this decrement in fit was due to the fact that the model did not adequately represent the relation between reasoning and fluency. Specifically, the negative signs of the corresponding residuals suggested that the model actually overestimated the degree of covariation between these two abilities. For this reason, we decided to introduce a residual covariance term between these 
Table 4

Summary of Model Fitting Procedure

\begin{tabular}{|c|c|c|c|c|c|c|c|c|}
\hline Model & Commentary & $\chi^{2}$ & $\Delta \chi^{2}$ & $d f$ & $p$ & NNFI & CFI & AODSR \\
\hline \multicolumn{9}{|c|}{ Measurement models } \\
\hline MM1 & Intercorrelated factor structure & 179.78 & & 67 & $<.001$ & .971 & .979 & .021 \\
\hline \multirow[t]{2}{*}{ MM2 } & Allowing for two correlated residuals & 139.25 & & 65 & $<.001$ & .980 & .986 & .017 \\
\hline & Comparison of MM2 with MM1 & & 40.53 & 2 & $<.001$ & & & \\
\hline \multicolumn{9}{|c|}{ Structural models } \\
\hline \multirow[t]{2}{*}{ HMl } & Hierarchical model with one second-order factor & 160.09 & & 70 & $<.001$ & .978 & .983 & .020 \\
\hline & Comparison of HM1 with MM2 & & 20.84 & 5 & $<.001$ & & & \\
\hline \multirow[t]{3}{*}{ HM2 } & $\begin{array}{l}\text { Same as HM1, but allowing for a residual } \\
\text { covariance term between reasoning and fluency }\end{array}$ & 146.29 & & 69 & $<.001$ & .981 & .985 & .018 \\
\hline & Comparison of $\mathrm{HM} 2$ with $\mathrm{HM} 1$ & & 13.80 & 1 & $<.001$ & & & \\
\hline & Comparison of HM2 with MM2 & & 7.04 & 4 & $>.05$ & & & \\
\hline
\end{tabular}

Note. $\quad N=516$. Model MM2 was accepted as the final measurement model, and model HM2, which is shown in Figure 1, was accepted as the final structural model. $\mathrm{MM}=$ measurement model; $\mathrm{HM}=$ hierarchical model; NNFI = nonnormed fit index or Tucker-Lewis Index; CFI = comparative fit index; AODSR = average off-diagonal standardized residuals.

two abilities. This modified hierarchical model (i.e., Model HM2 in Table 4) led to a significant improvement in fit over the original hierarchical model, $\Delta \chi^{2}(1, N=516)=13.81, p$ $<.01$. In addition, the fit of this modified hierarchical model did not differ significantly from the fit of the corresponding measurement model (i.e., MM2 in Table 4), $\Delta \chi^{2}(4, N=516$ ) $=7.04, p>.10$. Therefore, this model was accepted as an adequate structural representation of individual differences in intellectual functioning in this sample, $\chi^{2}(69, N=516)=$ $146.29, p<.01, \mathrm{NNFI}=.981, \mathrm{CFI}=.985, \mathrm{AODSR}=.018$. Figure 1 displays the structure and the path coefficients of this model in the standardized (i.e., correlational) metric.

Given the magnitude of the loadings of the five intellectual abilities on the General factor, ranging from .90 (perceptual speed) to .95 (fluency) in the standardized solution, one may wonder whether any of the five first-order Ability factors shared all of their variance with the General factor. To explore this issue, we examined the decrease in model fit after constraining the corresponding factor loadings to unity in the standardized solution. In each case, imposing such a constraint was associated with a significant loss in fit: reasoning, $\Delta \chi^{2}(1, N=516)=$ $87.47, p<.01$; perceptual speed, $\Delta \chi^{2}(1, N=516)=89.03, p$ $<.01$; memory, $\Delta \chi^{2}(1, N=516)=29.31, p<.01$; knowledge $\Delta \chi^{2}(1, N=516)=32.37, p<.01 ;$ and fluency, $\Delta \chi^{2}(1, N=$ $516)=34.44, p<.01$. Therefore, we can conclude that each of the five intellectual abilities contained (a relatively small portion of ) reliable variance that was truly specific to this particular ability, at least within the measurement space of intellectual abilities represented in this data set.

In another control analysis, we examined whether the loadings on the General factor could be constrained to be equal across the five abilities in the standardized solution. In this model, all five first-order abilities had factor loadings of .915 on the General factor. The fit of this equal-loadings model was quite satisfactory, $\chi^{2}(73, N=516)=185.62, \mathrm{NNFI}=.974, \mathrm{CFI}=.979$, AODSR $=.052$. However, this model fit the data significantly less well than the fit of the model without equality constraints, $\Delta \chi^{2}(4, N=516)=40.58, p<.01$. Thus, despite their similar- ity in magnitude, the relative contributions of the five intellectual abilities to the General factor were not numerically identical across all five abilities.

In summary, the hierarchical model of intelligence shown in Figure 1, with five hypothesized intellectual abilities at the firstorder level and a very strong factor of general intellectual ability at the second-order level, provided an adequate representation of individual differences in intellectual functioning. This result formalizes our impression that old-age intelligence, as measured by our battery, is characterized by a substantial and generalized increase in the magnitude and homogeneity of covariation among intellectual abilities. At the same time, we were able to demonstrate that the five intellectual abilities assessed in this study continue to exist, to some extent at least, as distinct dimensions of interindividual differences in intellectual functioning. From a psychometric perspective, these two findings suggest that age-based dedifferentiation operates as a second-order process: It leads to a dramatic increase in ability intercorrelations while preserving the existence and configuration of first-order intellectual abilities (cf. Schaie et al., 1989). ${ }^{3}$

Age differences in ability intercorrelations. To examine the possible existence of age-based differences in covariation among the five intellectual abilities within the BASE age spectrum, the total sample was split into two subsamples: one labeled as old $(n=258$; mean age $=77.5$ years, $S D=4.3$, and age range $=70-84$ years $)$, and the other labeled as very old $(n=$

\footnotetext{
${ }^{3}$ All of the model comparisons described in this subsection were also carried out with the reduced sample (i.e., without demented individuals, $n=407$ ). We obtained structurally identical results; that is, all model comparisons led to the same decisions. The fit for the final hierarchical model (i.e., model HM2 in Table 4) was again satisfactory, $\chi^{2}(69, N$ $=407)=127.94, p<.01, \mathrm{NNFI}=.977, \mathrm{CFI}=.982, \mathrm{AODSR}=.022$. As a consequence of the absence of demented individuals, the loadings of the five intellectual abilities on the General factor were somewhat lower than the loadings for the full sample: reasoning, .90 versus .92 ; perceptual speed, .87 versus .90 ; memory, .88 versus .93 ; knowledge, .90 versus .92 ; and fluency, .92 versus .95 .
} 
258 ; mean age $=92.4$ years, $S D=4.5$, and age range $=85-$ 103 years). First, we compared the magnitude of intellectual ability intercorrelations in the two groups at the level of unitweighted composites. The median correlation was .62 in the old and .63 in the very old sample, and there was no evidence for significant differences in the magnitude of ability intercorrelations between the two groups. When demented individuals were excluded from the analysis, the median correlation was .55 in the old group ( $n=236$; mean age $=77.2$ years, $S D=4.3$ ) and .57 in the very old group ( $n=171$; mean age $=91.8$ years, $S D=3.5$ ). Differences between groups were again not significant.

To enhance the statistical power in detecting existing group differences in covariation, we also examined the existence of group differences in ability intercorrelations at the latent level. For this purpose, we set up the final hierarchical model (i.e., Model HM2 in Table 4) as a two-group model and imposed strong (but not strict) metric invariance across groups (cf. Meredith, 1993). ${ }^{4}$ When loadings on the General factor were freely estimated (i.e., not constrained to be equal across groups), we obtained the following standardized factor loadings: reasoning, .90 (old) versus .87 (very old); perceptual speed, .86 versus .87 ; memory, .88 versus .88 ; knowledge, .92 versus .93 ; and fluency, .94 versus .94 . Each of the five factor loadings could be constrained to be equal in the standardized solution without a significant loss in fit; for all five tests: $\Delta \chi^{2}\left(1, N_{1}=258, N_{2}\right.$ $=258)<3.84, p>.05$. Factor loadings were of similar magnitude when individuals with a diagnosis of dementia were excluded from the analysis and again did not differ significantly between the two groups.

In summary, there was no evidence in favor of a significant increase in ability intercorrelations in the transition from old ( $70-84$ years) to very old ( $85-103$ years) age. Instead, ability intercorrelations were already very high in the old sample and did not differ significantly from those observed in the very old sample. Taken together, these two findings suggest that much of the observed integration or dedifferentiation of the intellectualability factor space occurs during the transition from adulthood into old age, rather than during the transition from old to very old age. For methodological reasons, however, we want to caution that the absence of a significant group difference in ability intercorrelations should not be portrayed as a confirmation of the null hypothesis of no age differences in ability intercorrelations. Specifically, it needs to be kept in mind that the data were inconsistent with the assumption of strict metric invariance and only met the criterion of strong metric invariance (cf. Meredith, 1993; see footnote 4).

\section{Age Differences in Interindividual Variability and Intraindividual Task Variability}

In this subsection, we examine the possible existence of age differences in interindividual variability (diversity) and intraindividual variability (dispersion). First, we examine whether the magnitude of interindividual differences increased or decreased as a function of age. Second, we introduce a measure of intraindividual task variability (i.e., within-subject, between-tasks dispersion) and examine the relation of this measure to age and ability level.
Age differences in interindividual variability (diversity). As reported above, about one third of the interindividual variability in intellectual functioning was related to chronological age. The highest relationship was found for perceptual speed, in which age accounted for $38 \%$ of the reliable variance. By implication, however, this also means that a substantial portion of interindividual differences was not related to chronological age, as demonstrated by the large amount of scatter around the regression lines in Figure 2. In fact, a few individuals performed exceptionally well for their age. For instance, with respect to perceptual speed, a 95-year-old performed one standard deviation above the mean of the 70-year-old individuals and 1.5 standard deviation units above the mean of the total sample. Another example is an 89-year-old who, together with a 73-year-old and a 77-year-old, obtained the highest score on the reasoning factor.

To examine whether the amount of interindividual variability increased or decreased with age, we regressed each of the five intellectual abilities and the unit-weighted composite of the five abilities (i.e., general intelligence) on age. To obtain a measure of interindividual variability, we then computed the rank order of the absolute deviations from the regression line. Table 5 shows the correlations of this deviation score with age; for descriptive purposes, the table also displays the standard deviations of old ( $70-84$ years) and very old ( $85-103$ years).

Overall, the magnitude of interindividual variability was remarkably stable. Specifically, perceptual speed, fluency, memory, and the general-intelligence composite did not evince any significant changes in interindividual variability with advancing age. Interindividual variability decreased with respect to reasoning $(r=-.30, p<.01)$ and slightly increased with respect to knowledge $(r=.13, p<.01)$. Further analyses not reported here showed that the observed pattern of results most likely was not entirely attributable to floor or ceiling effects. For instance, the decrease in interindividual variability for reasoning continued to be significant after excluding individuals diagnosed as demented $(r=-.25, p<.01)$ or after excluding all individuals

\footnotetext{
${ }^{4}$ Group comparisons at the latent level consisted of three steps. First, we checked whether the final hierarchical model (i.e., Model HM2 in Table 4) provided an adequate representation of the ability interrelations in each of the two groups by testing whether it was associated with a significant loss in fit compared with the measurement model (i.e., Model MM2 in Table 4). This was not the case: old, $\Delta \chi^{2}(4, N=516)=$ $13.27, p>.01$; very old, $\Delta \chi^{2}(4, N=516)=0.43, p>.01$. Second, we checked the assumption of strict metric invariance of the hierarchical model between groups (cf. Meredith, 1993), which implies equality of residual variances and covariances, first-order factor loadings, and firstorder factor specificities. Strict metric invariance did not hold because the residual variances of three tests-Letter Series, Figural Analogies, and Paired Associates - were significantly smaller in the very old sample (all $p \mathrm{~s}<.01$ ). Therefore, these three error variances were allowed to differ between the two groups, which resulted in strong metric invariance for the two-group comparison. In a third step, we conducted five separate tests to examine whether the loadings of a given intellectual ability on the General factor could be constrained to be equal across groups without resulting in a significant loss in fit. The identical procedure was followed with the reduced sample of research participants without dementia diagnosis $(n=407)$. In that analysis, only one of the three residual variances (i.e., the one for letter series) differed significantly across groups.
} 
Table 5

Age Differences in Interindividual Variability

\begin{tabular}{|c|c|c|c|c|c|}
\hline \multirow[b]{2}{*}{ Ability } & \multirow{2}{*}{$\begin{array}{l}\text { Age correlation of ranked } \\
\text { deviation scores }\end{array}$} & \multicolumn{2}{|c|}{$S D$} & \multicolumn{2}{|c|}{ Bartlett-Box test } \\
\hline & & Old (70-84 years) & Very old ( $85-103$ years) & $F(1,79588)$ & $F(1,459133)$ \\
\hline \multicolumn{6}{|c|}{ Mechanics (broad fiuid) } \\
\hline$n$ & $516(407)$ & $258(236)$ & $258(171)$ & & \\
\hline Perceptual speed & $.00(-.00)$ & $8.4(7.6)$ & $8.6(8.2)$ & 0.17 & $(1.18)$ \\
\hline Reasoning & $-.30(-.25)$ & $10.0(9.8)$ & $7.5(8.1)$ & 22.52 & $(7.39)$ \\
\hline Memory & $-.02(-.02)$ & $9.2(8.6)$ & $8.7(8.3)$ & 0.70 & $(0.24)$ \\
\hline \multicolumn{6}{|c|}{ Pragmatics (broad crystallized) } \\
\hline Knowledge & $.13(.12)^{*}$ & $8.9(8.1)$ & $9.8(8.9)$ & 2.21 & (1.74) \\
\hline Fluency & $-.06(-.08)$ & $9.3(8.9)$ & $9.1(8.4)$ & 0.23 & $(0.73)$ \\
\hline \multicolumn{6}{|c|}{ Composite } \\
\hline General intelligence & $-.04(-.05)$ & $8.8(7.9)$ & $8.5(7.8)$ & 0.26 & $(0.05)$ \\
\hline
\end{tabular}

Note. Values presented in boldfaced type were significant at the .01 level. Values in parentheses refer to analyses without individuals diagnosed as demented. Ranked deviation scores were obtained by regressing the given ability on age, saving the residuals, and computing the rank order of their absolute values. Positive correlations between deviation scores and age imply an increase in interindividual variability with age, whereas negative correlations imply a decrease. The right-hand side of the table reports the standard deviations of the intellectual-ability composites for old and very old participants. Standard deviations were normed to 10.0 in the full sample $(N=516)$. A Bartlett-Box $F$ test was used to test whether variances differed significantly across the two groups.

$* p=.016$.

with either missing values or zero scores on any one of the three tests of reasoning $(r=-.19, p<.01)$.

The predominant finding of age invariance in interindividual variability indicates that interindividual heterogeneity subsists into very old age but does not lend support to the stronger claim that individuals become more dissimilar as they age. Note, however, that most of the empirical evidence in support of this assertion has come from comparisons between young adults and young-old segments of the older population (cf. Morse, 1993; Nelson \& Dannefer, 1992). A recent study by Christensen et al. (1994) is an exception to this rule. Christensen et al. studied a sample of 897 community-dwelling individuals aged 70 years and over and found small but reliable increments in interindividual variability on factors of memory and broad fluid ability. A direct comparison between our and the Christensen et al. studies is rendered difficult by differences in sample composition and psychometric assessment.

Despite existing differences in procedure and outcome, however, the results of both the present study and the Christensen et al. (1994) research seem to indicate that age differences in interindividual variability of intellectual functioning are relatively small after age 70 . In our view, there are at least two reasons why trends toward increasing interindividual diversity may come to a halt in very old age. First, before age 70 , such an increase may reflect, in part, interindividual differences in the onset of the aging process. At later ages (e.g., in the 70$100+$ age range), most or all individuals may have evolved into a decline pattern of intellectual development (cf. Hertzog \& Schaie, 1988 , p. 128). As a consequence, interindividual differences in the onset of age-related cognitive decline as one specific source of diversity would be on the wane beyond age 70 . Second, selective mortality is likely to increasingly restrict the range of diversity at the lower end of the ability spectrum with advancing age and may counteract any subsisting tendency toward an increase in diversity with advancing age. Longitudinal data are required to test these considerations.

Age differences in intraindividual task dispersion. Many inquiries into the issue of ontogenetic changes in variability of performance focus on age-based differences in the degree of differences between individuals. However, it may be argued that the investigation of age-based differences in intraindividual task dispersion, or within-person, between-tasks variability, is equally important and often allows for a more direct test of underlying theoretical assumptions (P. B. Baltes et al., 1988; Buss, 1979; Nesselroade, 1991). To examine age differences in intraindividual task dispersion, we computed intraindividual standard deviations over the $z$-transformed scores of the 14 tests of the battery. Relatively low values on this intraindividual task dispersion score refer to relatively flat intraindividual profiles of intellectual performance, and relatively high values refer to relatively uneven performance profiles. To reduce the likelihood of artifactual associations with ability level, only test scores with nonmissing, nonzero values were considered in the computation of the intraindividual task dispersion score. If tests with zero scores had been included, any negative association between ability level and intraindividual task dispersion may have been due to floor effects. If estimated scores had been included, this also may have artifactually introduced a negative association between ability level and intraindividual task dispersion because low-ability participants were more likely to have missing values and because the replacement of missing values with linear regression estimates is accompanied by a decrease in intraindividual variability (unless multiple imputation techniques are used, which was not the case in this study). The standard deviation was preferred over the coefficient of variation (i.e., $S D / M$ ) as a measure of intraindividual task dispersion because the coeffi- 
cient of variation implicitly adopts a proportional relation between the variability and the mean as a baseline, which may seem justified in the context of reaction times but certainly is unjustified in the context of test scores.

Intraindividual task dispersion was negatively related to age ( $r=-.19, p<.01$ ) and positively related to general intelligence ( $r=.34, p<.01$ ). Age did not predict a significant amount of variance in intraindividual task dispersion when entered into the regression equation after general intelligence, $\Delta R^{2}=.000$, $F(1,514)=0.84, p>.10$. However, the Age $\times$ Intelligence interaction explained a significant amount of additional variance, $\Delta R^{2}=.022, F(1,513)=12.90, p<.01$.

To understand the nature of this interaction effect, we formed four different ability groupings on the basis of how well individuals performed intellectually for their age: (a) more than one standard deviation unit above the regression line of general intelligence on age ( $n=84)$, (b) between zero and one standard deviation units above the regression line $(n=176)$, (c) between zero and one standard deviation units below the regression line ( $n=170$ ), and (d) more than one standard deviation unit below the regression line $(n=86$ ). Figure 3 shows the age relations of the intraindividual task dispersion score for the four different ability groups. In the two low-performing groups, we observed significant negative relations between age and intraindividual task dispersion (i.e., $r=-.45$ for the lowest and -.32 for the second-lowest group, both $p$ s $<.01$ ). In contrast, the age relations of the two groups above the regression line did not differ significantly from zero at the .01 level (i.e., $r=.11, p>.05$ for the highest and $-.15, p=.047$ for the second-highest group).
As before, the Age $\times$ Ability Group interaction explained a significant amount of variance in intraindividual task dispersion beyond the main effects of group and age, $\Delta R^{2}=.024, F(1$, 513) $=14.09, p<.01$.

In summary, these analyses showed that interindividual differences in intraindividual variability interacted with age and general intelligence. Intraindividual task dispersion scores decreased with age in individuals whose intellectual performance was below average for their age but did not differ significantly as a function of age among individuals whose performance was above average for their age. One may wonder whether this interaction was a reflection of the age-based increase in the proportion of demented individuals in the sample. However, in contrast to this interpretation, the Age $\times$ Ability Group interaction continued to be significant in the reduced, nondemented sample ( $n$ $=407), \Delta R^{2}=.019, F(1,513)=8.14, p<.01$.

As can be seen in Figure 3, intraindividual task dispersion did not differ much as a function of ability level among the younger individuals of this sample. In fact, the correlation between general intelligence and intraindividual task dispersion was more positive in the $85-103$ age range $(r=.42)$ than in the 70-84 age range $(r=.17)$; for the difference between the two correlations, $z=3.03, p<.01$.

A general way to interpret these findings is to conceive of interindividual differences in dispersion scores as indicators of dedifferentiation at the level of the individual normed against the variability of the sample (because the $z$ transformation of the 14 tests indirectly introduces interindividual variance into the measure). When viewed from this perspective, the present

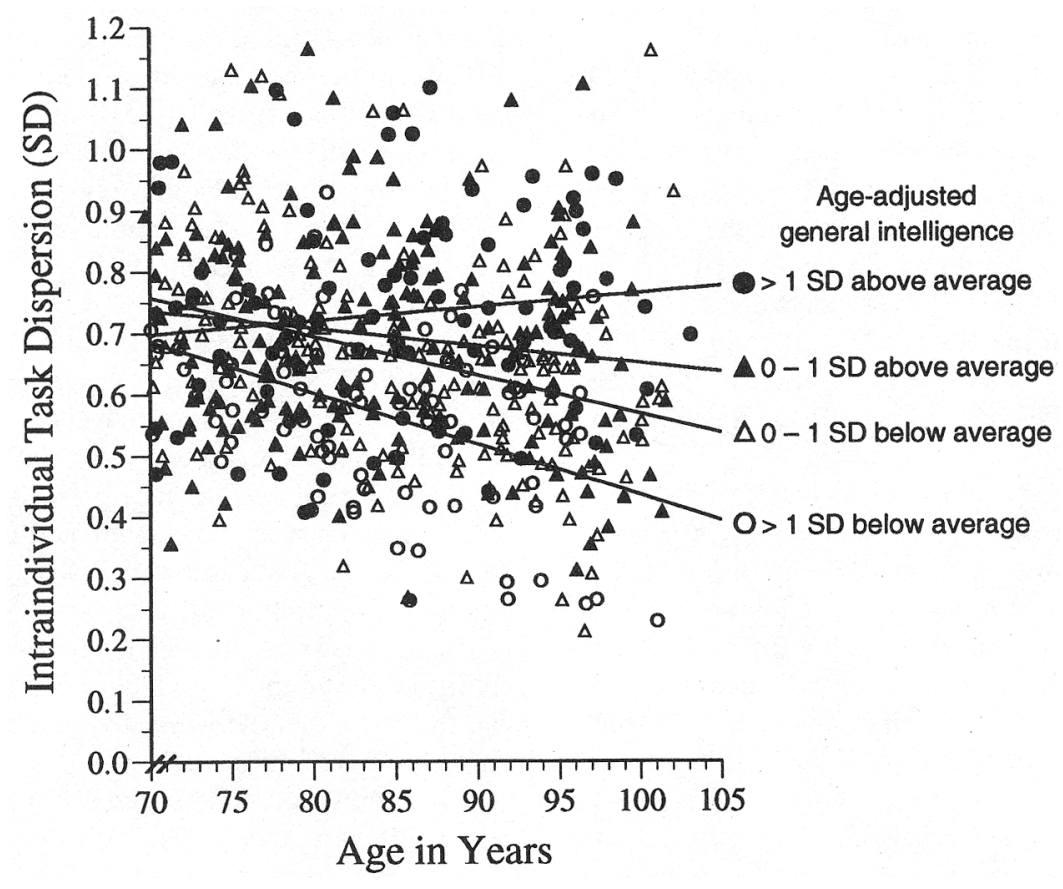

Figure 3. Age differences in intraindividual task dispersion interact with ability level. Intraindividual task dispersion (i.e., within-subject variability) refers to intraindividual standard deviations over the $14 z$ transformed ability test scores. Ability level refers to how well individuals performed intellectually for their age. Profile flattening with advancing age is found in individuals who perform below the mean on general intelligence relative to their age. 
findings indicate that very old, low-ability participants have the most dedifferentiated pattern of intellectual performance because they are most likely to perform at a level that is uniformly low across all tests of the battery. Historically, this dedifferentiation of task profiles in very old, low-ability individuals is consistent with the so-called ability differentiation hypothesis put forward in the 1960s (Reinert, Baltes, \& Schmidt, 1965, 1966; Wewetzer, 1968). In light of our methodological precautions in computing the intraindividual task dispersion score, we hold it unlikely that this late-life flattening of the ability profile in lowability individuals primarily reflects a floor effect in the technical sense of a measurement artifact. Rather, we think that this phenomenon represents a drastic consequence of a domain-general set of central-nervous system constraints. On the more positive side, the significant Age $\times$ Ability interactions and the positive association between degree of dispersion and level of intellectual functioning, especially in very old participants, indicated that this flattening of performance profiles is not ubiquitous. Taken together, these findings may help to understand the absence of an age-based increase in ability intercorrelations in this sample.

\section{Relationship of Intellectual Abilities to Dementia Diagnosis and Dementia Severity}

So far, individuals with a clinical diagnosis of dementia were routinely included in the analyses reported in this article. This procedure was justified by the argument that aging, as a population process, comprises both demented and nondemented individuals and by the notion that the validity of any clinical diagnosis of dementia is far from perfect. Although we believe that this general approach is defensible, it remains of interest to know whether dementia diagnosis, and dementia severity, were differentially related to the five intellectual abilities assessed in this study. Note, however, that the cognitive battery of BASE was not designed with the primary goal to optimize the discrimination between normal and pathological cognitive aging and that detailed dementia-related analyses of the BASE data set using more specific measures of amnestic and apractic syndromes are reported elsewhere (Lindenberger \& Reischies, in press; Reischies \& Lindenberger, 1996).

In the total sample, point-biserial correlations of dementia diagnosis ( $0=$ absent, $1=$ present $)$ with intellectual functioning were as follows: memory, $r=-.53$; perceptual speed, $r=-.52$; fluency, $r=-.50$; knowledge, $r=-.49$; and reasoning, $r=$ -.40 . After controlling for age, relations were reduced in magnitude: memory, $r=-.43$; fluency, $r=-.41$; perceptual speed, $r=-.40$; knowledge, $r=-.40$; and reasoning, $r=-.28$. Contrary to expectations (cf. Christensen, Hadzi-Pavlovic, \& Jacomb, 1991), memory, in this set of analyses, did not differ significantly in its relation to dementia diagnosis from fluency, perceptual speed, and knowledge: first-order correlations, $z=$ $1.02, p>.10$; age-partialed correlations, $z=0.93, p>.10$. However, reasoning was more weakly related to dementia diagnosis than the other four intellectual abilities: first-order correlations, $z=4.50, p<.01$; and age-partialed correlations, $z=$ $4.69, p<.01$.

Within the group of individuals with dementia diagnosis ( $n$ $=109$ ), degree of diagnosis severity ( 1 [very mild to mild], 2 [moderate], to 3 [severe]) was negatively related to all five intellectual abilities - raw correlations: memory, $r=-.53$; fluency, $r=-.50$; perceptual speed, $r=-.42$; knowledge, $r=$ -.29 ; and reasoning, $r=-.29$ and age-partialed correlations: memory, $r=-.52$; fluency, $r=-.49$; perceptual speed, $r=$ -.40 ; knowledge, $r=-.28$; and reasoning, $r=-.28$. Memory and fluency were more highly related to dementia severity than reasoning, knowledge, and perceptual speed: raw correlations, $z=3.35, p<.01$; age-partialed correlations, $z=3.36, p<$ .01 .

\section{Correlates of Intellectual Functioning in Old and Very Old Age}

We now turn to the correlates of intellectual functioning in old and very old age. Many theoretical conceptions about the structure and life span ontogenesis of intellectual functioning posit two interrelated but distinct systems of influence: the biological and the cultural. The two systems are seen as antecedents, correlates, and consequents of intellectual functioning, and they jointly contribute to the overdetermined, or "compound" (Horn, 1989), character of human intelligence (P. B. Baltes, 1987, 1993; cf. P. B. Baltes et al., in press; Berg \& Sternberg, 1985; Cattell, 1971; Horn, 1982; Hunt, 1993; Rybash, Hoyer, \& Roodin, 1986).

In line with these conceptions, we expected that mechanic and pragmatic intellectual abilities are differentially related to biological and sociobiographical correlates. Specifically, we assumed that knowledge, as a key marker ability of the pragmatic (broad crystallized) domain, should closely be related to individual differences in past and concurrent sociostructural status and experience. On the other hand, perceptual speed, as a marker ability of the mechanics, should evince a particularly close link to cognition-extraneous indicators of aging-induced biological decrements in brain functioning. Therefore, we predicted (a) that the relationship of knowledge to sociobiographical correlates of intellectual functioning is stronger than the relationship of perceptual speed to the same set of correlates and (b) that that the relationship of perceptual speed to biological correlates of intellectual functioning is stronger than the corresponding relationship of knowledge.

Within the presumably more biologically dominated set of correlates, balance-gait, hearing, and vision were chosen to represent individual differences in the domain of sensory-sensorimotor functioning. As expected, the three sensory-sensorimotor variables and the four sociobiographical variables (i.e., income, occupational prestige, social class, and years of education) fell into two distinct groups ( see Table 6). For instance, exploratory factor analyses (i.e., principal-axis extraction followed by oblique rotation) yielded two, moderately intercorrelated factors $(r=.26)$. The divergent nature of the two sets of correlates was further corroborated by the fact that the sensorysensorimotor variables, but not the sociobiographical variables, were substantially related to chronological age.

The effect of life history differences on negative age differences in intellectual functioning late in life: Is age kinder to the initially or currently advantaged? A recurring hypothesis in gerontological research is that individuals with high standing on desirable life history or sociobiographical dimensions such 
Table 6

Intercorrelations Among Sociobiographical and Sensory-Sensorimotor Variables

\begin{tabular}{lccccccc}
\hline \multicolumn{1}{c}{ Variable } & 1 & 2 & 3 & 4 & 5 & 6 & 7 \\
\hline 1. Occupational prestige & - & .51 & .57 & .30 & .17 & .17 & .22 \\
2. Years of education & .51 & - & .46 & .29 & .20 & .15 & .25 \\
3. Social class & .58 & .47 & - & .24 & .06 & .15 & .17 \\
4. Income & .30 & .29 & .24 & - & .14 & $\mathbf{. 0 7}$ & .15 \\
5. Balance-gait & .15 & .15 & $\mathbf{. 0 8}$ & .15 & - & .46 & .53 \\
6. Hearing & .15 & .09 & .19 & .06 & .14 & - & .45 \\
7. Vision & .21 & .22 & .21 & .16 & .23 & .17 & - \\
\hline
\end{tabular}

Note. $\quad N=516$. Values not significantly different from zero at the .01 level are in boldfaced type. First-order correlations are shown above, whereas age-partialed correlations are shown below the main diagonal.

as social status, social participation, or initial level of cognitive functioning are less likely to experience age-associated decrements in intellectual performance than individuals who score low on any of these dimensions. According to this line of thought, age is "kinder to the initially more able" (Owens, 1959 , p. 334). Most of the available longitudinal and crosssectional evidence on this issue does not lend support to this expectation. Instead, with some notable exceptions (e.g., Kohn \& Schooler, 1978, 1983), the results of numerous investigations seem to suggest that individuals scoring high on desirable dimensions show just about the same amount of age changes (Gribbin, Schaie, \& Parham, 1989; Siegler, 1983) or age differences (Christensen \& Henderson, 1991; Fozard \& Nuttal, 1971; Owens, 1959; Salthouse et al., 1990; Salthouse, Kausler, \& Saults, 1988) as individuals with relatively low scores. For the age period of old and very old age, little information about this issue has been available so far.

In the BASE sample, all four sociobiographical life history variables were positively related to general intelligence (see Table 7). Among the four, years of education and occupational prestige were more highly correlated with general intelligence than social class and income $(z=3.64, p<.01)$. The multiple correlation of the four correlates with general intelligence was substantial $(r=.48, p<.01)$. To examine the link of the sociobiographical variables to general intelligence, we computed a unit-weighted composite over the four sociobiographical variables and compared individuals who scored above the mean ( $n=234$ ) with those who scored below $(n=282)$. The difference in general intelligence between these two groups amounted to somewhat less than a standard deviation (effect $\operatorname{size}_{S D}=$ $0.91), t(1)=10.27, p<.01$.

As is shown in Figure 4, the slope of the cross-sectional age gradients in general intelligence observed in this data set did not vary significantly as a function of social life history information. The figure displays two freely estimated regression lines: one for individuals above and the other for individuals below the mean on the index of sociobiographical differentiation introduced above. The relation of general intelligence to age was identical in the two groups, $r=.58, p<.01 .^{5}$

On the one hand, then, past and present sociocultural differences continue to be associated with interindividual differences in intellectual functioning after age 70 . On the other hand, there was no evidence, in this cross-sectional analysis, to suggest that advantages in life history and current sociocultural context protect against age-based reductions in intellectual performance. From a psychometric perspective, then, our findings suggest that the age periods of old and very old age are not kinder to the initially or presently advantaged. However, a threshold view of the matter, which may be more adequate for a variety of practical, ethical, or theoretical reasons, may lead to an opposite interpretation of the same data pattern. According to that interpretation, the sociobiographically more advantaged are much less likely to end up with levels of intelligence that no longer permit an independent life, exactly because they carry a (presumably constant) advantage into very old age (cf. M. Baltes \& Lang, 1997). Finally, note that our findings of age constancy in the association between social status and intelligence were based on cross-sectional data and that longitudinal analyses may yield a different picture.

Biological factors: The intersystemic link to sensory and sensorimotor functions. As can be seen in Table 7, the three sensory-sensorimotor variables showed an even more substantial link to general intelligence than the sociobiographical life history variables (multiple $r=.69$ ). In contrast, general somatic morbidity was only weakly related to intelligence $(r=-.14, p$ $<.01)$, and amount of medication did not show a significant relationship ( $r=-.00$ ).

In addition to being strongly related to general intelligence, the sensory-sensorimotor variables and the index of brain atrophy were also strongly related to age. This constellation of variable relations is further explored in the two right-hand columns of Table 7. The values represented in these columns are derived on the basis of linear regression and indicate how much of the age-related variance of a given correlate (e.g., balancegait) is predicted by general intelligence, and vice versa. It is difficult to test whether such pairs of age-based variance proportions differ significantly from each other because they are scaled against different amounts of total variance. In any case, the magnitude of these estimates suggests a high degree of age-based commonality between measures of intelligence, sensory-sensorimotor functioning, and brain atrophy (for methodological problems with variance-partitioning procedures of this kind, see Lindenberger \& Pötter, 1997).

Another way to illustrate the predominantly age-based connection between the sensory-sensorimotor variables and general intelligence is to compare the age gradients of general intelligence before and after controlling for individual differences in vision, hearing, and balance-gait. As can be seen in Figure 5, controlling for individual differences on these three variables reduced the age relation from $r=-.57$ to $r=-.06(p>.05)$.

In summary, these analyses replicated earlier findings based

\footnotetext{
${ }^{5}$ To examine the robustness and the generality of this finding, additional analyses were computed with other statistical procedures (e.g. hierarchical regression with a continuous rather than dichotomous representation of the independent variable and two-group structural models ), different dependent variables (perceptual speed and knowledge rather than general intelligence), and different independent variables (personality variables such as openness to experience, extroversion, and neuroticism; social participation; and age-corrected intelligence). With no exception, interactions with age fell far from statistical significance.
} 
Table 7

Correlates of Intellectual Functioning in Old and Very Old Age

\begin{tabular}{|c|c|c|c|c|c|}
\hline \multirow[b]{2}{*}{ Variable } & \multicolumn{3}{|c|}{ Correlation with $g$} & \multicolumn{2}{|c|}{ Age-based variance } \\
\hline & $\begin{array}{l}\text { First } \\
\text { order }\end{array}$ & $\begin{array}{c}\text { Age } \\
\text { partialed }\end{array}$ & $\begin{array}{l}\text { Correlation } \\
\text { with age }\end{array}$ & $\begin{array}{c}\text { In variable } \\
\text { predicted by } g(\%)\end{array}$ & $\begin{array}{l}\text { In } g \text { predicted } \\
\text { by variable }(\%)\end{array}$ \\
\hline \multicolumn{6}{|l|}{ Sociobiographical } \\
\hline Occupational prestige & .41 & .44 & -.08 & & \\
\hline Years of education & .39 & .38 & .14 & & \\
\hline Social class & .29 & .35 & .00 & & \\
\hline Income & .28 & .31 & -.04 & & \\
\hline Multiple $R$ & .48 & & & & \\
\hline \multicolumn{6}{|l|}{ Sensory-sensorimotor } \\
\hline Balance-gait & .59 & .36 & -.66 & 63.3 & 82.6 \\
\hline Hearing & .51 & .28 & -.57 & 64.5 & 64.5 \\
\hline Vision & .57 & .36 & -.59 & 70.4 & 74.5 \\
\hline Multiple $R$ & .69 & & & & \\
\hline \multicolumn{6}{|l|}{ Medical-biological } \\
\hline Brain atrophy index $x^{a}$ & -.44 & -.20 & .51 & 53.4 & 63.1 \\
\hline Number of diagnoses & -.14 & -.08 & .13 & & \\
\hline Amount of medication & -.00 & .04 & .05 & & \\
\hline
\end{tabular}

Note. $N=516$. The first column denotes the correlation of the variables with general intelligence $(g)$, the second the age-partialed correlation of variable with $g$, the third the correlation between the variable and age, the fourth the proportion of age-based variance in the variable predicted by $g$, and the fifth the proportion of age-based variance in $g$ predicted by the variable. Values for the fourth and fifth columns were computed only if the correlation of the variable with age exceeded $|20|$. Values not significantly different from zero are in boldfaced type.

${ }^{a}=254$.

on the initial subsample of 156 BASE research participants (Lindenberger \& Baltes, 1994b), demonstrating again that indicators of sensory-sensorimotor functioning emerge as powerful correlates of intelligence in old and very old age. One may wonder whether the magnitude of these relations was primarily due to the fact that a substantial portion of the total sample suffered from very poor hearing or very poor vision (cf. Marsiske \& Klumb, 1997). However, in additional control analyses, we found no evidence to suggest that associations between sensory-sensorimotor functioning, general intelligence, and age de-

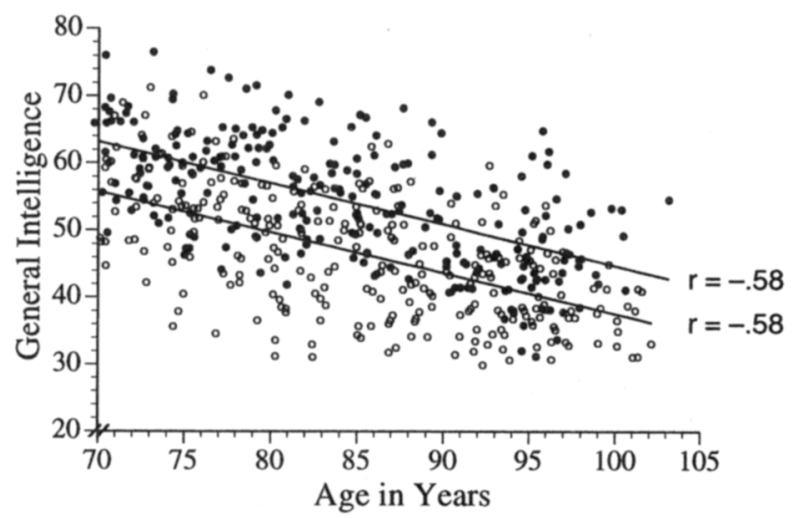

Figure 4. Is age kinder to the socially and biographically advantaged (cf. Owens, 1959)? Perhaps not. The figure displays the freely estimated regression lines of general intelligence on age for individuals who performed above (filled circles) and below (unfilled circles) the mean on a unit-weighted composite of four sociobiographical indicators. creased with increasing sensory-sensorimotor or intellectual performance levels (cf. Lindenberger \& Baltes, 1994b).

Elsewhere (P. B. Baltes \& Lindenberger, 1997; Lindenberger \& Baltes, 1994b), we have argued that the magnitude and the age-relatedness of this intersystemic connection point to the existence of a set of more general, brain-related mechanisms that regulate the aging process in both domains. From this perspective, the sensory-sensorimotor variables are good predictors (in the statistical sense) of age-based differences in general intelligence in old and very old age because they happen to be good indicators of this general set of mechanisms. This interpretation receives additional support by the significant connection of brain atrophy to intelligence and age (cf. Raz et al., 1993). ${ }^{6}$

Sociobiographical differences and sensory-sensorimotor functioning as correlates of old-age intelligence: A direct comparison. A commonality analysis (Pedhazur, 1982) was computed to determine the shared and unique contributions of the main effects of the two sets of correlates to individual differences in general intelligence. Specifically, the three sensorysensorimotor and the four sociobiographical correlates were added blockwise and in both orders as predictors into a linear regression equation with the general intelligence composite serving as the dependent variable. Thirty-four percent of the

\footnotetext{
${ }^{6}$ Note that the link of general intelligence to sensory-sensorimotor functioning and brain atrophy was not entirely due to the similarity of cross-sectional age gradients in the two domains of functioning. Thus, statistically controlling for individual differences in chronological age did not eliminate the intersystemic link between sensory-sensorimotor and cognitive functioning (see column 2 in Table 7).
} 

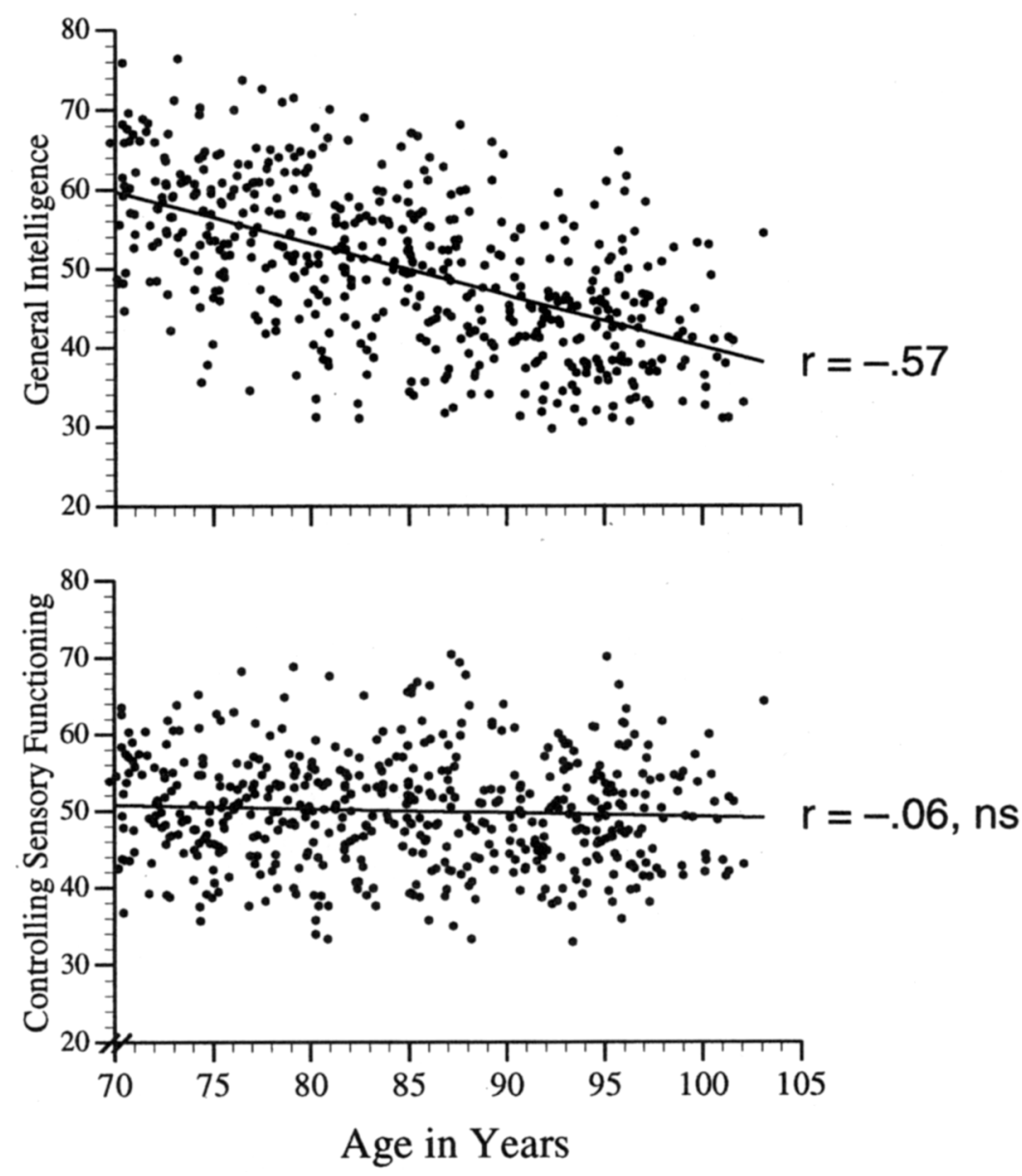

Figure 5. The age relation of individual differences in general intelligence before and after controlling for main effects of balance-gait, hearing, and vision.

total variance in general intelligence was uniquely related to sensory-sensorimotor functioning, $9 \%$ was uniquely related to sociobiographical differences, and $14 \%$ was shared with both sets of correlates. Taken together, the two sets of correlates explained more than half (i.e., 56\%) of the total variance in general intelligence. When age was added into the prediction equation, the amount of explained variance increased to $58 \%$ $\left(\Delta R^{2}=.015\right), F(1,508)=17.99, p<.01$.

One may argue that the predominance of sensory-sensorimotor variables over sociobiographical variables as predictors of intellectual functioning may reflect differences in the relative proximity of the two sets of measures to the intellectual outcome variable. According to this line of reasoning, more proximal measures of social participation would show stronger relations to intellectual functioning. Analyses reported elsewhere (M. Baltes, Maas, Wilms, Borchelt, \& Little, in press; M. Baltes, Mayr, Borchelt, Maas, \& Wilms, 1993; Lindenberger \& Baltes, 1995) confirmed this expectation. For instance, the five intellectual abilities were found to predict $45 \%$ of the total variance in social participation in the present sample. However, social participation was closely linked to age $(r=-.56)$ and showed stronger relations to vision $(r=.53)$, hearing $(r=.44)$, and balance ( $r=.59$ ) than to education $(r=.27)$, social class ( $r$ $=.21)$, occupational prestige $(r=.27)$, and income $(r=.24$; $z=10.44, p<.01$ ). On the basis of these findings, it appears that individual differences in proximal measures of social participation were more strongly related to concurrent aging-induced changes than to general differences in the social biography of the research participants.

Ability-specific relations to sociobiographical and sensorysensorimotor variables: Evidence for divergent external validity. We now turn to the issue of whether the sociobiographical and sensory-sensorimotor variables assessed in this study were differentially related to mechanic and pragmatic intellectual abilities, as two-component models of intellectual development would predict (P. B. Baltes, 1993; Cattell, 1971; Horn, 1982). In a first analysis, we chose knowledge as a marker ability of the cognitive pragmatics and perceptual speed as a marker of the cognitive mechanics to examine whether these two intellectual abilities were differentially related to sensory-sensorimotor and sociobiographical variables. The selection of these two intellectual abilities was guided by theoretical and empirical considerations. Thus, perceptual speed is generally regarded as a highly aging-sensitive ability in the broad fluid domain (Salthouse, 
1991 ), whereas general semantic knowledge is often seen as a reliably measured and socially relevant ontogenetic acquisition.

The emerging correlational pattern was fully consistent with our expectations (see Figure 6): Perceptual speed evinced stronger relations to the sensory-sensorimotor variables than knowledge, and knowledge was more strongly related to the sociobiographical variables than perceptual speed. The relevant statistical tests, which compared the correlations of perceptual speed and knowledge to the seven variables, were significant throughout: balance-gait, $z=5.88$; hearing, $z=2.75$; vision, $z=3.69$; income, $z=-2.40$; occupational prestige, $z=-4.14$; social class, $z=-3.37$; and years of education, $z=-3.15$; for all $z$ values, $p<.01$.

These analyses clearly demonstrated that perceptual speed and knowledge were differentially related to sociobiographical and sensory-sensorimotor correlates of intellectual functioning. Specifically, at least two of the five intellectual abilities assessed in this study displayed meaningful specificity despite the fact that more than $80 \%$ of their reliable variance was shared with other intellectual abilities.
Another outcome of this first analysis was that both perceptual speed, but also knowledge, appeared to be more strongly related to sensory-sensorimotor functioning than to sociobiographical differences, suggesting a preponderance of sensory-sensorimotor over sociobiographical differences with respect to all five intellectual abilities. To examine this issue more closely, and to better control for differences.in reliability between the two sets of correlates, we set up a latent model with a factor of sensorysensorimotor functioning defined by balance-gait, hearing, and vision; a factor of sociobiographical factor defined by income, occupational prestige, social class, and years of education; and the five intellectual-ability factors defined by their corresponding tests. The fit of this model was quite acceptable, $\chi^{2}(166$, $N=516)=304.14, \mathrm{NNFI}=.974, \mathrm{CFI}=.979, \mathrm{AODSR}=.023$.

Table 8 displays the amount of reliable (i.e., latent-factor) variance shared between the five intellectual abilities, on the one hand, and sensory-sensorimotor functioning and a sociobiographical factor, on the other. Three findings are noteworthy. First, all five intellectual abilities were again more strongly related to sensory-sensorimotor functioning than to the sociobio-

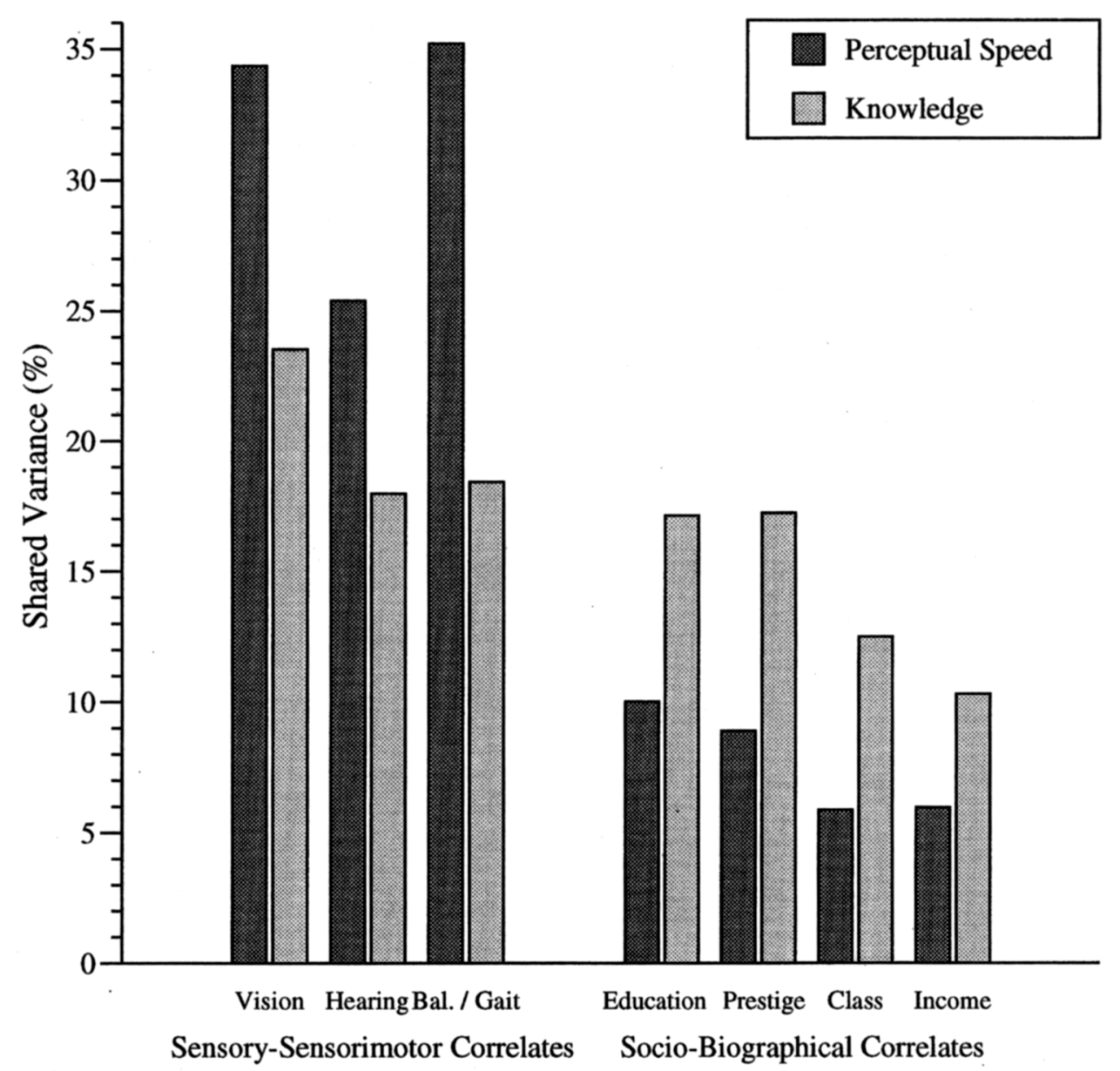

Figure 6. The divergent external validity of the two-component model of life span intellectual development subsists into very old age. The figure displays differential correlational links of perceptual speed, a marker of the mechanic (broad fluid) domain, and knowledge, a marker of the pragmatic (broad crystallized) domain, to sociobiographical and biological (e.g., sensory) variables. Bal. = balance. 
Table 8

Relations of Intellectual Abilities to Sociobiographical and Sensory-Sensorimotor Correlates: Amounts of Shared Variance in Percentages Between Latent Constructs

\begin{tabular}{lccr}
\hline \multicolumn{1}{c}{ Ability } & Sociobiographical & $\begin{array}{c}\text { Sensory- } \\
\text { sensorimotor }\end{array}$ & $z$ \\
\hline \multicolumn{4}{c}{ Mechanics (broad fluid) } \\
Perceptual speed & 19.4 & 72.4 & 13.46 \\
Reasoning & 22.8 & 57.9 & 8.28 \\
Memory & 17.7 & 52.6 & 8.24 \\
\hline \multicolumn{4}{c}{ Kragmatics (broad crystallized) } \\
Knowledge & 37.5 & 50.4 & \\
Fluency & 22.7 & 59.9 & 8.01 \\
\hline
\end{tabular}

Composite

Average of all five intellectual abilities 23.9 59.1 8.34

Note. Results are based on a measurement model with a latent factor of sociobiographical differentiation defined by income, occupational prestige, social class, and years of education; a latent factor of sensorysensorimotor functioning defined by balance-gait, hearing, and vision; and five intellectual-ability factors defined by the corresponding tests. The fit of the model was acceptable, $\chi^{2}(166, N=516)=304.14$, nonnormed fit index $=.974$, comparative fit index $=.979$, average offdiagonal standardized residuals $=.023$. The sociobiographical and the sensory-sensorimotor factors had $12 \%$ of their variance in common. As indicated by the $z$ values, all five intellectual abilities were more strongly associated with sensory-sensorimotor functioning than with the sociobiographical factor.

graphical factor, suggesting that the previous finding for knowledge and perceptual speed was not just a consequence of differences in reliability between the two sets of correlates. The magnitude of the relationship between perceptual speed and sensory-sensorimotor functioning was especially impressive: The two constructs shared $72 \%$ of their variance. Second, we replicated the finding that the link between perceptual speed and sensory-sensorimotor functioning was more pronounced than the link between knowledge and sensory-sensorimotor functioning ( $z=9.64, p<.01$ ). Likewise, the link between knowledge and sociobiographical differences was more pronounced than the link between perceptual speed and the sociobiographical factor $(z=7.95, p<.01)$. Finally, the remaining three intellectual abilities showed less distinct correlational profiles, and there was some some unexpected cross-over between mechanic and pragmatic abilities. Specifically, fluency was more strongly related to sensory-sensorimotor functioning than memory $(z=3.64, p<.01)$ but did not differ from reasoning in its relation to the sociobiographical factor $(z=0.04, p>$ .10 ), which provides further support for the hybrid, rather than predominantly pragmatic, nature of this ability (Salthouse, 1993).

Correlates of intellectual functioning in old and very old age: A summary model. To summarize the relations among age, sensory-sensorimotor functioning, sociobiographical differences, and intelligence in this data set, we conclude the Results section with an overall structural model. As before, sociobiographical differences were indexed by social class, education, occupational prestige, and income; sensory-sensorimotor functioning by vision, hearing, and balance; and the five intellectual abilities by the corresponding tests. The structural relations among the latent constructs of the model are shown in Figure 7.

In this model, chronological age and the sociobiographical factor function as independent variables. It is assumed that age differences in intelligence are connected to sensory-sensorimotor functioning to such a degree that all of the age-related variance in intellectual functioning is shared with the sensorysensorimotor factor (i.e., it is assumed that the unique effects of age on intellectual functioning after controlling for individual differences in sensory-sensorimotor functioning do not differ significantly from zero). In addition, we expected a specific link between sensory-sensorimotor functioning and perceptual speed, reflecting the close connection between the two domains of functioning. Finally, on the basis of the results of the commonality analysis reported above, the sociobiographical factor was expected to be related to general intelligence but also to the sensory - sensorimotor factor. In addition, individual differences captured by the sociobiographical factor were assumed to be specifically linked to knowledge.

The resulting model fit the data quite well, $\chi^{2}(196, N=516)$ $=372.80, \mathrm{NNFI}=.971, \mathrm{CFI}=.975, \mathrm{AODSR}=.037$, and explained $66 \%$ of the total reliable variance in general intelligence. The chi-square difference to the corresponding measurement model was small but statistically significant, $\Delta \chi^{2}(16, N$ $=516)=35.22, p=.004$. More important, however, all the paths between latent constructs that were not included in the model, such as the correlation between age and the sociobiographical factor (in which its presence would have pointed to the existence of cohort effects), the direct paths from age to general intelligence or from age to the five intellectual abilities, as well as the remaining paths from sensory-sensorimotor functioning and the sociobiographical factor to any of the five intellectual abilities, did not differ significantly from zero (all $p \mathrm{~s}$ $>.01)$

\section{Summary of Findings}

The main goal of this study was to describe the cross-sectional age gradients, structure, and correlates of intellectual abilities in old and very old age obtained in the Berlin Aging Study. Many findings were novel, but most of them in the limited sense that observations made at younger ages were extended into very old age.

From the perspective of life span theory (P. B. Baltes et al., in press), our findings can be summarized under the general headings of continuity versus discontinuity as well as preserved differentiation versus dedifferentiation. According to continuity and preserved-differentiation views, intelligence in old and very old age is assumed to be characterized by predictive, functional, and structural continuity to earlier phases of life. In support of this view, we found (a) that the different intellectual abilities continue to exist as distinct dimensions of interindividual differences at the first-order level, (b) that there is no general tendency toward a decrease in between-persons variability, and (c) that life history differences assessed by sociobiographical variables 


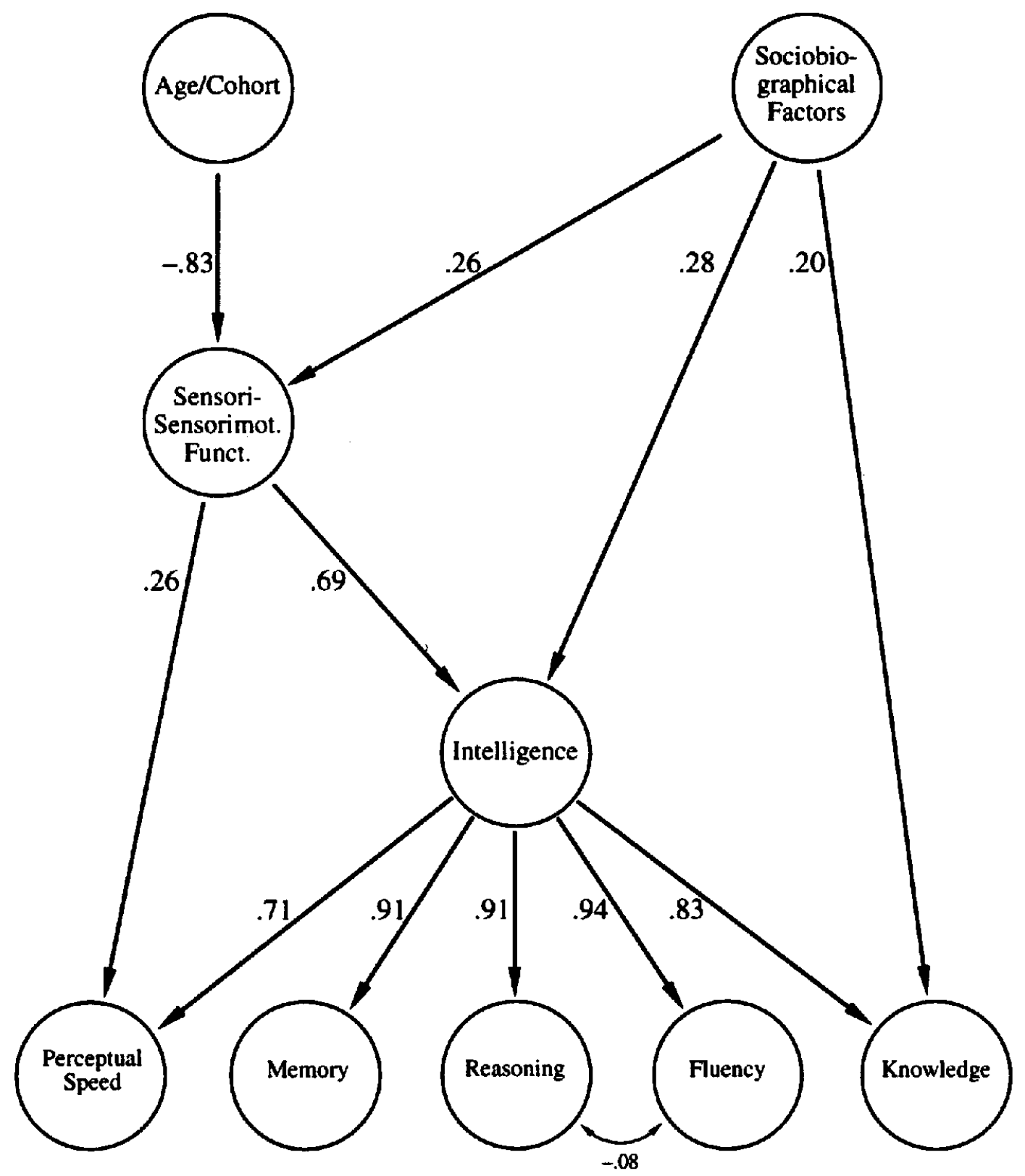

Figure 7. Correlates of intellectual functioning in old and very old age: a structural model. Only latent constructs are shown in the figure. The fit of the model was acceptable, $\chi^{2}(196, N=516)=372.80$, nonnormed fit index $=.971$, cumulative fit index $=.975$. Sensori-Sensorimot. Funct. $=$ Sensory-sensorimotor functioning.

continue to be associated to intelligence in general and to knowledge in particular.

In contrast, the discontinuity and dedifferentiation views posit that old-age intelligence is primarily dominated by aging-induced changes in brain integrity. Albeit such changes are probably present throughout ontogeny, their increasing importance with advancing age is assumed to impose a common and general constraint on many different aspects of intellectual functioning and to transform old-age intelligence into a distinct develop- mental phenomenon. In agreement with that view, we found (a) that the age gradients of predominantly mechanic (broad fluid) and predominantly pragmatic (broad crystallized) intellectual abilities converge to yield a picture of generalized linear decrement (directionality dedifferentiation), (b) that this picture applies to samples both above and below the average on sociobiographical life history variables, (c) that the intercorrelations among intellectual abilities are of greater magnitude and uniformity than commonly observed during earlier phases of life and 
are well described by a single factor of general intelligence (structural dedifferentiation at the second-order level), (d) that sensory and sensorimotor variables in combination share about $57 \%$ of their total reliable variance with the general factor of intelligence (cf. P. B. Baltes \& Lindenberger, 1997; Lindenberger \& Baltes, 1994b), and (e) that intraindividual task dispersion was especially low (e.g., dedifferentiated) in very old and low-ability participants.

Taken together, these findings appear to support the theoretical position that cognitive aging is a relatively unitary and general process, especially within the age period of old and very old age (cf. Li, Lindenberger, \& Frensch, 1996; Salthouse, 1996). However, given the interpretational ambiguity associated with cross-sectional, correlational data (Hertzog, 1996; Lindenberger \& Pötter, 1997), additional evidence based on other methods, such as longitudinal, experimental, and simulation designs, is needed to further examine the tenability of this position.

\section{Limitations of the Present Study}

This study has several limitations. With respect to measures, for instance, it was conceived, for the most part, within the psychometric research tradition. Therefore, its findings may not generalize directly to other research traditions within the field of cognitive aging. Note, however, that the tests included in our cognitive battery overlap considerably with the kinds of tasks used in more experimentally oriented work (cf. Craik \& Salthouse, 1992; Salthouse, 1991 ).

With respect to design, we highlight again the pitfalls and constraints of cross-sectional studies (cf. P. B. Baltes et al,, 1988; Hertzog, 1996). With respect to this study, three limitations are especially relevant. First, cross-sectional data sets do not permit direct inferences about intraindividual change and interindividual differences in intraindividual change. Second, cross-sectional age differences represent complex outcomes of multiple systems of influence and change. In old and very old age, pathological (rather than "normal") aging processes, selective mortality, and generational cohort effects are all likely to be involved. Third, longitudinal (e.g., life history) interpretations of cross-sectional age differences are necessarily retrospective in character and need to be corroborated by converging evidence from other sources.

By now, longitudinal follow-up investigations of the sample reported in this study are underway. In addition, we keep track of the mortality history of the research participants of BASE. It is hoped that the combined analysis of mortality and longitudinal follow-up information will shed further light on the ways in which intraindividual changes, mortality, and generational differences contribute to the age-related cross-sectional differences observed in this study (cf. Keiding, 1991; Nesselroade, 1991).

\section{References}

American Psychiatric Association. (1987). Diagnestic and statistical manual of mental disorders (3rd ed., rev.). Washington, DC: Author. Baltes, M. M., \& Lang, F. R. ( 1997). Everyday functioning and successful aging: The impact of resources. Psychology and Aging, 12, 433443.

Baltes, M. M., Maas, I., Wilms, H.-U., Borchelt, M., \& Little, T. D. (in press). Everyday competence in old and very old age: Theoretical considerations and empirical findings. In P. B. Baltes \& K. U. Mayer (Eds.), The Berlin Aging Study: Aging from 70 to 100. New York: Cambridge University Press.

Baltes, M. M., Mayr, U., Borchelt, M., Maas, I., \& Wilms, H.-U. ( 1993). Everyday competence in old and very old age: An inter-disciplinary perspective. Ageing and Society, 13, 657-680.

Baltes, P. B. (1987). Theoretical propositions of life-span developmental psychology: On the dynamics between growth and decline. Developmental Psychology, 23, 611-626.

Baltes, P. B. (1993). The aging mind: Potential and limits. The Gerontologist, 33, 580-594.

Baltes, P. B., Cornelius, S. W., Spiro, A., Nesselroade, J. R., \& Willis, S. L. (1980). Integration versus differentiation of fluid/crystallized intelligence in old age. Developmental Psychology, 16, 625-635.

Baltes, P. B., \& Lindenberger, U. (1997). Emergence of a powerful connection between sensory and cognitive functions across the adult life span: A new window to the study of cognitive aging? Psychology and Aging, 12, 12-21.

Baltes, P. B., Lindenberger, U., \& Staudinger, U. M. (in press). Lifespan theory in developmental psychology. In R. M. Lerner (Ed.), Theoretical models of human development: Handbook of child pisychology (5th ed., Vol. 1). New York: Wiley.

Baltes, P. B., Mayer, K. U., Helmchen, H., \& Steinhagen-Thiessen, E. (1993). The Berlin Aging Study (BASE): Overview and design. Ageing and Society, 1.3, 483-515.

Baltes, P. B., Mayer, K. U., Helmchen, H., \& Steinhagen-Thiessen, E. (1996). Die Berliner Altersstudie (BASE): Überblick und Einfürung [The Berlin Aging Study (BASE): Overview and introduction]. In K. U. Mayer \& P. B. Baltes (Eds.), Die Berliner Altersstudie (pp. 21-54). Berlin: Akademie Verlag.

Baltes, P. B., Reese, H. W., \& Nesselroade, J. R. (1988). Life-span developmental psychology: An introduction to reseurch methods (2nd ed.). Hillsdale, NJ: Erlbaum.

Baltes, P. B., \& Smith, J. ( 1997). A systemic-wholistic view of psychological functioning in very old age: Introduction to a collection of articles from the Berlin Aging Study. Psychology and Aging, 12, 395409

Beale, E. M. L., \& Little, R. J. (1975). Missing values in multivariate analysis. Journal of the Royal Statistical Society. Series B, 37, 129 145.

Berg, C. A., \& Sternberg, R. J. ( 1985). A triarchic theory of intellectual development during adulthood. Developmental Review, 5, 334-370.

Buss, A. R. (1979). Toward a unified framework for psychometric concepts in the multivariate developmental situation: Intraindividual change and inter- and intraindividual differences. In J. R. Nesselroade \& P. B. Baltes (Eds.), Longitudinal research in the study of behavior and development (pp. 41-59). New York: Academic Press.

Carroll, J. B. (1993). Human cognitive abilities. Cambridge, MA: Cambridge Lniversity Press.

Cattell, R. B. (1971). Abilities: Their structure, growth, and action. Boston: Houghton Mifflin.

Christensen, H., Hadzi-Pavlovic, D., \& Jacomb, P. (1991). The psychometric differentiation of dementia from normal aging: A meta-analysis. Psychological Assessment: A Journal of Consulting and Clinical Psychology, 3, 147-155.

Christensen, H., \& Henderson, A. S. (1991). Is age kinder to the initially more able? A study of eminent scientists and academics. Psychological Medicine, 21, 935-946.

Christensen, H., Mackinnon, A., Jorm, A. F., Henderson, A. S., Scott, L. R., \& Korten, A. E. (1994). Age differences and interindividual variation in cognition in community-dwelling elderly. Psychology and Aging, 9, 381-390.

Craik, F. I. M., \& Salthouse, T. A. (1992). (Eds.). The handbook of aging and cognition. Hillsdale, NJ: Erlbaum. 
Deary, I. J., \& Pagliari, C. (1991). The strength of $g$ at different levels of ability: Have Detterman and Daniel rediscovered Spearman's "law of diminishing returns"'? Intelligence 15, 251-255.

Folstein, M. F., Folstein, S., \& McHugh, P. R. (1975). "Mini-Mental State"; A practical method for grading cognitive status of patients for the clinician. Joumal of Psychiatric Research, 12, 189-198.

Fozard, J. L., \& Nuttal, R. L. (1971). General Aptitude Test Battery scores for men differing in age and socioeconomic status. Journal of Applied Psychology, 55, 372-379.

Garrett, H. E. (1946). A developmental theory of intelligence. American Psychologist, 1, 372-378.

Geigy Pharmaceuticals. (1977). Wissenschaftiche Tabellen [Scientific tables ]. Basel, Switzerland: Author.

Gribbin, K., Schaie, K. W., \& Parham, I. A. (1989). Complexity of life style and maintenance of intellectual abilities. Journal of Social Issues, 36, 47-61.

Hebb, D. O. (1949). The organization of behavior. New York: Wiley.

Helmchen, H., Baltes, M. M., Geiselmann, B., Kanowski, S., Linden, M., Reischies, F. M., Wagner, M., \& Wilms, H.-U. (1996). Psychische Erkrankungen im Alter [Psychiatric illness in old age]. In K. U. Mayer \& P. B. Baltes (Eds.), Die Berliner Altersstudie (pp. 185219). Berlin: Akademie Verlag.

Herlitz, A., Nilsson, L.-G., \& Bäckman, L. (in press). Gender differences in episodic memory. Memory \& Cognition.

Hertzog, C. (1996). Research design in studies of aging and cognition. In J. E. Birren \& K. W. Schaie (Eds.), Handbook of the psychology of aging (4th ed., pp. 24-37). New York: Academic Press.

Hertzog, C., \& Schaie, K. W. (1988). Stability and change in adult intelligence: 2 . Simultaneous analysis of longitudinal means and covariance structures. Psychology and Aging, 3, 122-130.

Horn, J. L. (1982). The theory of fluid and crystallized intelligence in relation to concepts of cognitive psychology and aging in adulthood. In F. I. M. Craik \& S. Trehub (Eds.), Aging and cognitive processes (pp. 237-278). New York: Plenum Press.

Horn, J. L. (1989). Models of intelligence. In R. L. Linn (Ed.), Intelligence: Measurement, theory, and public policy (pp. 29-73). Urbana: University of Illinois Press.

Hunt, E. ( 1993 ). What do we need to know about aging? In J. Cerella, J. Rybash, W. Hoyer, \& M. L. Commons (Eds.), Adult information processing: Limits on loss (pp. 587-598). San Diego, CA: Academic Press.

Keiding, N. (1991) . Age-specific incidence and prevalence: A statistical perspective. Journal of the Royal Statistical Society A, 154, 371-412.

Kohn, M. L., \& Schooler, C. (1978). The reciprocal effects of the substantive complexity of work and intellectual flexibility: A longitudinal assessment. American Journal of Sociology, 84, 24-52.

Kohn, M. L., \& Schooler, C. (1983). Work and personality. Norwood, NJ: Ablex.

Kruse, A., Lindenberger, U., \& Baltes, P. B. (1993). Longitudinal research on human aging: The power of combining real-time, microgenetic, and simulation approaches. In D. Magnusson \& P. Casaer (Eds.), Longitudinal research on individual development (pp. 153-193). New York: Cambridge University Press.

Li, S.-C., Lindenberger, P., \& Frensch, P. A. (1996). In search of an integrative framework of cognitive aging: A computational exploration of the link between processing efficiency and brain catecholamines. Unpublished manuscript.

Lienert, G. A., \& Crott, H. W. (1964). Studies on the factor structure of intelligence in children, adolescents, and adults. Vita Humana, 7 . 147-163.

Linden, M., Gilberg, R., Horgas, A. L., \& Steinhagen-Thiessen, E. (1996). Die Inanspruchnahme medizinischer und pflegerischer Hilfe im Alter [The utilization of medical care in old age]. In K. U. Mayer \&
P. B. Baltes (Eds.), Die Berliner Altersstudie (pp. 475-495). Berlin: Akademie Verlag.

Lindenberger, U., \& Baltes, P. B. (1994a). Aging and intelligence. In R. J. Stemberg et al. (Eds.), Encyclopedia of intelligence (pp. 5266). New York: MacMillan.

Lindenberger, U., \& Baltes, P. B. (1994b). Sensory functioning and intelligence in old age: A strong connection. Psychology and Aging, 9. 339-355.

Lindenberger, U., \& Baltes, P. B. (1995). Kognitive Leistungsfähigkeit im hohen Alter: Erste Ergebnisse von der Berliner Altersstudie [Cognitive functioning in very old age: First results from the Berlin Aging Study]. Zeitschrift für Psychologie, 203, 283-317.

Lindenberger, U., Gilberg, R., Little, T. D., Nuthmann, R., Pötter, U., \& Baltes, P. B. (in press). Sample selectivity and generalizability of results from the Berlin Aging Study. In P. B. Baltes \& K. U. Mayer (Eds.), The Berlin Aging Study: Aging from 70 to 100. New York: Cambridge University Press.

Lindenberger, U., Gilberg, R., Pötter, U., Little, T. L., \& Baltes, P. B. (1996). Stichprobenselektivität und Generalisierbarkeit der Ergebnisse in der Berliner Altersstudie [Sample selectivity and generalizability of results in the Berlin Aging Study]. In K. U. Mayer \& P. B. Baltes (Eds.), Die Berliner Altersstudie (pp. 85-108). Berlin: Akademie Verlag.

Lindenberger, U., Mayr, U., \& Kliegl, R. (1990). Validation of the cognitive battery of the Berlin Aging Study: Results from a pilot study (Tech. Report). Berlin: Max-Planck-Institut für Bildungsforschung.

Lindenberger, U., Mayr, U., \& Kliegl, R. (1993). Speed and intelligence in old age. Psychology and Aging, 8, 207-220.

Lindenberger, U., \& Pötter, U. (1997). The complex nature of unique and shared effects in hierarchical linear regression: Consequences for cross-sectional developmental research. Unpublished manuscript.

Lindenberger, U., \& Reischies, F. M. (in press). Limits and potentials of intellectual functioning in old age. In P. B. Baltes \& K. U. Mayer (Eds.), The Berlin Aging Study: Aging from 70 to 100. New York: Cambridge University Press.

Marsiske, M., Delius, J., Maas, I., Lindenberger, U., Scherer, H., \& TeschRömer, C. (1996). Sensorische Systeme im Alter [ Sensory systems in old age ]. In K. U. Mayer \& P. B. Baltes (Eds.), Die Berliner Altersstudie (pp. 379-403). Berlin: Akademie Verlag.

Marsiske, M., Klumb, P., \& Baltes, M. M. (1997). Everyday activity patterns and sensory functioning in old age. Psychology and Aging, $12,444-457$.

Mayer, K. U., \& Wagner, M. (1993). Socio-economic resources and differential ageing. Ageing and Society, 13, 517-550.

Mayer, K. U., \& Wagner, M. (1996). Lebenslagen und soziale Ungleichheit im Alter [Life conditions and social inequality in old age]. In K. U. Mayer \& P. B. Baltes (Eds.), Die Berliner Altersstudie (pp. 251-275). Berlin: Akademie Verlag.

McArdle, J. J., \& Woodcock, R. W. (in press). Expanding test-retest designs to include developmental time-lag components. Psychological Methods.

McClelland, G. H., \& Judd, C. M. (1993). Statistical difficulties of detecting interactions and moderator effects. Psychological Bulletin, $114,376-390$.

Meng, X.-L., Rosenthal, R., \& Rubin, D. B. (1992). Comparing correlated correlation coefficients. Psychological Bulletin, 111, 172-175.

Meredith, W. (1993). Measurement invariance, factor analysis, and factorial invariance. Psychometrika, 58, 525-543.

Merz, F., \& Kalveram, K. T. (1965). Kritik der Differenzierungshypothese der Intelligenz [Critique of the differentiation hypothesis of intelligence ]. Archiv der Gesamten Psychologie, 117, 287-295.

Morse, C. K. ( 1993). Does variability increase with age? An archival study of cognitive measures. Psychology and Aging, 8, 156-164.

Nelson, E. A., \& Dannefer, D: (1992). Aged heterogeneity: Fact or 
fiction? The fate of diversity in gerontological research. The Gerontologist, 32, 17-23.

Nesselroade, J. R. (1991). Interindividual differences in intraindividual change. In L. M. Collins \& J. L. Horn (Eds.), Best methods for the analysis of change: Recent advances, unanswered questions, future directions (pp. 92-105). Washington, DC: American Psychological Association.

Nuthmann, R., \& Wahl, H.-W. (1996). Methodische Aspekte der Erhebungen der Berliner Altersstudie. In K. U. Mayer \& P. B. Baltes (Eds.), Die Berliner Altersstudie (pp. 55-83). Berlin: Akademie Verlag.

Owens, W. A. (1959). Is age kinder to the initially more able? Journal of Gerontology, 14, 334-337.

Pedhazur, E. J. (1982). Multiple regression in behavioral research. New York: Holt.

Perfect, T. J. (1994). What can Brinley plots tell us about cognitive aging? Journal of Gerontology: Psychological Sciences, 49, P60P64.

Raz, N., Torres, I. J., Spencer, W. D., Millman, D., Baertschi, J. C., \& Sarpel, G. (1993). Neuroanatomical correlates of age-sensitive and age-invariant cognitive abilities: $A n$ in vivo MRI investigation. Intelligence, 17, 407-422.

Reinert, G. (1970). Comparative factor analytic studies of intelligence throughout the life span. In L. R. Goulet \& P. B. Baltes (Eds.), Lifespan developmental psychology: Research and theory (pp. 476-484). New York: Academic Press.

Reinert, G., Baltes, P. B., \& Schmidt, L. R. (1965). Faktorenanalytische Untersuchungen zur Differenzierungshypothese der Intelligenz: Die Leistungsdifferenzierungshpyothese [Factor analytic investigations of the differentiation hypothesis of intelligence: Achievement differentiation hypothesis]. Psychologische Forschung, 28, 246-300.

Reinert, G., Baltes, P. B., \& Schmidt, L. R. (1966). Kritik einer Kritik der Differenzierungshypothese der Intelligenz [Critique of a critique of the differentiation hypothesis of intelligence]. Zeitschrift für Experimentelle und Angewandte Psychologie, 13, 602-610.

Reischies, F. M., \& Lindenberger, U. (1996). Grenzen und Potentiale kognitiver Leistungsfähigkeit im Alter [Limits and potentials of cognitive functioning in old age]. In K. U. Mayer \& P. B. Baltes (Eds.), Die Berliner Altersstudie (pp. 351-377). Berlin: Akademie Verlag.

Reischies, F. M., Rossius, W., \& Felsenberg, D. (1997). CT parameters of persons with and without dementia in a population-based sample of very old adults. Unpublished manuscript.

Rovine, M. J., \& Delaney, M. (1990). Missing data estimation in developmental research. In A. V. Eye (Ed.), Statistical methods in longitudinal research (pp. 35-79). San Diego, CA: Academic Press.

Rudinger, G., \& Rietz, C. (1995). Intelligenz: Neuere Ergebnisse aus der Bonner Längsschnittstudie des Alterns (BOLSA) [Intelligence: New results from the Bonn Longitudinal Study on Aging (BOLSA)]. In A. Kruse \& R. Schmitz-Scherzer (Eds.), Psychologie des Lebenslaufs (pp. 197-211). Darmstadt, Germany: Steinkopf.

Rybash, J. M., Hoyer, W. J., \& Roodin, P. A. (1986). Adult cognition and aging: Developmental changes in processing, knowing, and thinking. New York: Pergamon Press.

Salthouse, T. A. (1991). Theoretical perspectives on cognitive aging Hillsdale, NJ: Erlbaum.

Salthouse, T. A. (1993). Speed and knowledge as determinants of adult age differences in verbal tasks. Journal of Gerontology: Psychological Sciences, 48, 29-36.

Salthouse, T. A. (1996). The processing-speed theory of adult age differences in cognition. Psychological Review, 103, 403-428.

Salthouse, T. A., Babcock, R. L., Skovronek, E., Mitchell, D. R. D., \& Palmon, R. (1990). Age and experience effects in spatial visualization. Developmental Psychology, 26, 128-136.

Salthouse, T. A., Kausler, D. H., \& Saults, J. S. (1988). Investigation of student status, background variables, and the feasibility of standard tasks in aging research. Psychology and Aging, 3, 29-37.

Schaie, K. W. (1996). Intellectual development in adulthood: The Seattle Longitudinal Study. New York: Cambridge University Press.

Schaie, K. W., Willis, S. L., Jay, G., \& Chipuer, H. (1989). Structural invariance of cognitive abilities across the adult life span: A crosssectional study. Developmental Psychology, 25, 652-662.

Siegler, I. C. (1983). Psychological aspects of the Duke longitudinal studies. In K. W. Schaie (Ed.), Longitudinal studies of adult psychological development (pp. 136-190). New York: Guilford Press.

Siegler, I. C., \& Botwinick, J. (1979). A long-term longitudinal study of intellectual ability of older adults: The matter of selective subject attrition. Journal of Gerontology, 34, 242-245.

Spearman, C. E. (1927). The abilities of man. New York: MacMillan.

Steinhagen-Thiessen, E., \& Borchelt, M. (1996). Morbidität, Medikation und Funktionalität im Alter [Morbidity, medication, and functional capacity in old age]: In K. U. Mayer \& P. B. Baltes (Eds.), Die Berliner Altersstudie (pp. 151-183). Berlin: Akademie Verlag.

Tinetti, M. E. (1986). A performance-oriented assessment of mobility problems in elderly patients. Joumal of the American Geriatrics Society, 34, 119-126.

Wagner, G., Motel, A., Spieß, K., \& Wagner, M. (1996). Wirtschaftliche Lage und wirtschaftliches Handeln alter Menschen [The economic situation and economic activity of the elderly]. In K. U. Mayer \& P. B. Baltes (Eds.), Die Berliner Altersstudie (pp. 301-319). Berlin Akademie Verlag.

Wegener, B. (1985). Gibt es Sozialprestige? [Dues social prestige exist?] Zeitschrift fü Soziologie, 14, 209-235.

Wewetzer, K. H. (1968). Die Faktorenstruktur der Intelligenz in ihrer Abhängigkeit von der Begabungsart. Ein Beitrag zur Typenanalyse [The factor structure of intelligence as a function of type of giftedness. A contribution to typological analysis ]. In K. J. Groffmann \& K. H. Wewetzer (Eds.), Person als Prozess (pp. 213-230). Berne, Switzerland: Huber.

Received August 20, 1996

Revision received January 10, 1997 Accepted January 10, 1997 